Illinois State University

ISU ReD: Research and eData

Theses and Dissertations

3-23-2015

\title{
Waking Dormant Researchers: Student Co-Research as Writing Research Methodology and Pedagogy
}

Angela Renee Sheets

Illinois State University, ms.angela.sheets@gmail.com

Follow this and additional works at: https://ir.library.illinoisstate.edu/etd

Part of the Communication Technology and New Media Commons, Curriculum and Instruction Commons, and the Educational Methods Commons

\section{Recommended Citation}

Sheets, Angela Renee, "Waking Dormant Researchers: Student Co-Research as Writing Research Methodology and Pedagogy" (2015). Theses and Dissertations. 377.

https://ir.library.illinoisstate.edu/etd/377

This Thesis is brought to you for free and open access by ISU ReD: Research and eData. It has been accepted for inclusion in Theses and Dissertations by an authorized administrator of ISU ReD: Research and eData. For more information, please contact ISUReD@ilstu.edu. 


\section{WAKING DORMANT RESEARCHERS: STUDENT \\ CO-RESEARCH AS WRITING RESEARCH \\ METHODOLOGY AND PEDAGOGY}

Angela R. Sheets

130 Pages

May 2015

This thesis explores the ways that students took up writing researcher skills, knowledges, and identities through a teacher-student co-research investigation of writing in an online writing research course. The following questions guided this study:

- How did literate activity occur in an online Composition as Critical Inquiry Course?

- What writing research skills, knowledges, and identities did the students take up and demonstrate as they participated in a co-research project?

The study also examined the efficacy of co-research as a methodology and pedagogy. Chapter 1 reviews literature from the relevant English studies fields. Central topics include the rationale for writing research pedagogies, an exploration of co-research (the primary methodology for this project), and an overview of online writing courses (OWCs).

Chapter 2 describes the methods and methodologies used in this study. It begins with a rationale and description of the course that served as the site of the co-research investigation followed by a description of the methods used in the study. For the first 
research question, the students were invited to investigate literate activity in our OWC and report their findings in journal articles. For the second research question, four students participated in a focus group where they were asked to describe the writing research skills, knowledges, and identities they developed during the course.

Chapter 3 presents results and discussion related to the first research question. Findings from six student co-research projects are presented along with a discussion of the affordances and limitations of each co-researchers' work.

Chapter 4 presents results and discussion related to the second research question. Students took up an awareness of genres/contexts, research methods, and self-knowledge. This chapter also examines the extent to which the students took up conscious writing researcher identities.

The thesis concludes with recommendations about co-research as methodology and pedagogy. 
WAKING DORMANT RESEARCHERS: STUDENT

CO-RESEARCH AS WRITING RESEARCH

METHODOLOGY AND PEDAGOGY

ANGELA R. SHEETS

A Thesis Submitted in Partial

Fulfillment of the Requirements

for the Degree of

MASTER OF ARTS

Department of English

ILLINOIS STATE UNIVERSITY

2015 
Copyright 2015 Angela R. Sheets 
WAKING DORMANT RESEARCHERS: STUDENT

CO-RESEARCH AS WRITING RESEARCH

METHODOLOGY AND PEDAGOGY

ANGELA R. SHEETS

COMMITTEE MEMBERS:

Joyce R. Walker, Chair

Bob Broad 


\section{ACKNOWLEDGMENTS}

As my co-researcher Wes points out in his study, writing is never a solo sport. With that in mind, I would like to acknowledge the support and help of several people who helped make this thesis project possible.

First, I owe a great deal of gratitude to Dr. Joyce Walker for both her scholarship and her support as a mentor on this project. Thank you for equipping me with both the framework and opportunity I needed to set this project in motion. I don't think I can ever un-be the person I became when I crossed the CHAT threshold.

I am also deeply indebted to Dr. Bob Broad. Thank you for assigning the readings that got me started thinking about co-research in the first place and for your calming assistance through the IRB process.

A few colleagues that I can think of (and probably others that I can't think of) also deserve mention. I feel like my project somewhat picks up where Laurenn Jarema's thesis left off. So, thank you, Laurenn for the groundwork you laid on transfer in our writing program. I also appreciate your allowing me to use your materials as "genre research" on "how to thesis." I also owe a great deal to Julie Bates, who (along with her coresearchers) explored the co-research methodology with me.

Thanks to my husband, Daniel, for reminding me to eat and drink tea when I was too "in the zone" to remember to do so. 
Finally, I cannot say enough to express my gratitude to my co-researchers, Adela, Wes, Katie, Sam, Claire, Mark, and Joe. Thank you for your time, your work, your insights, and your wisdom. Your voices are the life of this project.

A.R.S. 


\section{CONTENTS}

Page

ACKNOWLEDGMENTS

CONTENTS

FIGURES $\quad$ V

INTRODUCTION

CHAPTER

I. WRITING RESEARCH PEDAGOGY GOES ONLINE:

A LITERATURE REVIEW

Writing Research Model 5

$\begin{array}{lr}\text { Co-Research Methodology } & 12\end{array}$

Constructing Knowledge in Online Writing Courses 19

$\begin{array}{ll}\text { Setting the Stage } & 25\end{array}$

II. STUDENTS AS RESEARCHERS:

METHODOLOGY AND METHODS 26

$\begin{array}{ll}\text { The Course } & 27\end{array}$

Question 1 Methods 33

Question 2 Methods $\quad 35$

Meet the Researchers $\quad 40$

Concluding Thoughts $\quad 45$

III. WHAT WE LEARNED ABOUT OUR CLASS TOGETHER:

CO-RESEARCH AS METHODOLOGY 46

Adela's Study: "How Were Our Discussions

Different on Google Drive vs. ReggieNet?" 47

Wes's Study: "Where Would This Article Be

without Peer-Evaluation?"

50

Katie's Study: “Underlying Identity: Online vs. 
Face-to-Face Classes"

Claire and Sam's Study: "Being an Introvert in an Online Class"

Mark's Study: “Are We Aware?"

Joe's Study: "How to Hit a Home Run in Uptake"

Synthesis of Our Findings

Reflecting on Co-Research as Methodology

IV. BECOMING WRITING RESEARCHERS:

CO-RESEARCH AS PEDAGOGY

Awareness of Genres and Contexts

Research Methods

80

Self-Knowledge

87

Writing Researcher Identity Uptake

98

Concluding Thoughts

A FUTURE FOR CO-RESEARCH?

CONCLUSIONS AND RECOMMENDATIONS

APPENDIX A: Uptake Blog Assignment

APPENDIX C: Genre Analysis Assignment 


\section{FIGURES}

Figure $\quad$ Page

1. Student generated list of skills and knowledges 38

2. Students identifying genre characteristics 71

3. Descriptions of genre research $\quad 72$

4. Student awareness of genre performance 73

5. Examples of CHAT understanding and performance 75

6. Detailed description of technological mediation 77

7. Descriptions of technology use during research process 77

8. Awareness of limitations of technologically mediated environments 78

9. Descriptions of the possible audiences of GWRJ 79

10. Student expectations about the usefulness of databases 81

11. Discussions of decisions not to use survey data 84

12. Descriptions of data analysis approaches 85

13. Joe's defense of methodology and descriptions of methods 87

14. Students identifying what they do not know 89

15. Transferring antecedent genre knowledge 91

16. Transferring affective knowledge and research strategies 92

17. Use of brainstorming and outlining 94

18. Mark's use of notes 95 
19. Joe's use of process genres in interviews 96

20. Student awareness of work environments 97

21. Discussions of time management 98

22. Statements about writing researcher identities in class blogs 101 


\section{INTRODUCTION}

Ensuring that new college students have adequate writing skills has been the perennial task of first year composition, also known as FYC (Bartholomae, 2007). For years, the pedagogy that dominated FYC was the notion that teaching students general writing skills would allow them to write in any context. Over the past few decades, however, numerous studies in the field of Rhetorical Genre Studies (RGS) have illuminated the theory that writing is an activity learned socially in specific contexts (Miller, 1984; Freedman, 1993a; Russell, 1995; Bawarshi \& Reiff, 2010). These findings suggest that the general writing skills taught in FYC may not transfer easily or at all into new writing situations (Russell, 1995; Bergmann \& Zepernick, 2007). So, what does transfer? Downs \& Wardle (2007) suggest that there is promise in the writing about writing pedagogy, which encourages students to take a scholarly approach to understanding writing as an object of study. Illinois State University's Writing Program takes Downs \& Wardle's concept a step further, focusing on writing research. In this paradigm, students are encouraged to cultivate research skills and to take up writing researcher identities that allow them to robustly analyze writing (both academic and nonacademic) and its relationship to complex settings (Walker, 2014).

As the field is grappling with these issues, we are also trying to explore the most effective methods for teaching FYC in digital spaces because demand for online classes is increasing. Despite the abundant research that advocates for the use of social- 
constructivist pedagogies online (e.g., Warnock, 2009; Pachler \& Daly, 2011; Swenson \& Taylor, 2012), research also suggests that many online writing courses (OWC) still position the instructors as the central experts who must bestow their vast knowledge on the ignorant students (e.g., DePew \& Lettner-Rust, 2009; Gillam \& Wooden, 2013; Remley, 2014). However, implementing a social-constructivist pedagogy in online spaces also demands that instructors and, as some claim, students (Van Ittersum \& Lawson Ching, 2013) take up a critical awareness of how learning and literate activity happen in online spaces (e.g., Brown, 2006; Griffin \& Minter, 2013).

Bearing in mind issues of effective FYC instruction in general and FYC in online spaces in particular, this thesis explores the ways that students took up writing researcher skills, knowledges, and identities through a teacher-student co-research investigation of writing in an online writing research course. The following questions guided this study:

- Question 1: How did literate activity occur in an online Composition as Critical Inquiry course?

- Question 2: What writing research skills, knowledges, and identities did the students take up and demonstrate as they participated in a co-research project?

In addition to these central questions, the study also examined the efficacy of co-research as a methodological and pedagogical approach. A type of participatory research, coresearch invites participants to conceive of themselves as researchers (Boylorn, 2007). As Ray (1992) describes working with student researchers, "Students are not merely subjects whom the teacher researcher instructs and assess; they are co-researchers, sources of knowledge whose insights help focus and provide new directions for the study" (pp. 175 176). The rationale behind using a co-research model was two-fold. First, inviting students to act as fellow researchers afforded them greater agency in the investigation as they were invited to help shape the research questions and the trajectories of the research 
results. Second, inviting students to conduct their investigations alongside a more experienced writing researcher (the instructor) may have helped scaffold their acquisition of writing research skills.

Chapter 1 of this thesis is a review of literature from the field. I trace the development of genre studies and writing research pedagogies, establishing the rationale for the move from teaching writing to teaching writing research. Next, I provide background on co-research, which serves as the primary methodology for this project. Finally, I offer a brief overview of research on OWCs. This section provides a foundation for the rationale behind the course that was taught in this study, and it also serves as a backdrop against which the reader might compare the student co-researchers' investigations into online literate activity.

Chapter 2 describes the methods and methodologies used in this study. I begin by offering a rationale and description of the course that served as the site of study for this investigation. I then detail the methods used to explore the two central research questions mentioned above. For the first research question, I invited students to design, carry out, and write up research investigations about a literate activity in the course. For the second research question, I held a focus group with students from the course at which I asked them to describe the writing research skills, knowledges, and identities they developed during the course. I then used the results of that discussion to code the students' work from the semester.

Chapter 3 presents results and discussion related to the first research question. I present findings from six student research projects, which centered on issues of learning management systems, peer review, self-representation in online courses, and uptake. At 
the end of the chapter, I explore the affordances and limitations of co-research that were made evident in this project.

Chapter 4 presents results and discussion related to the second research question. Drawing on evidence from the focus group and the students' course documents, I argue that the students took up an awareness of genres/contexts, research methods, and selfknowledge. In the final portion of this chapter, I examine the extent to which the students took up conscious writing researcher identities.

I conclude with recommendations based on the findings and proposals for future research.

This study offers the field valuable access to student voices and perspectives on learning management systems, peer interactions in online spaces, self-representation online, and uptake. Additionally, it offers writing research pedagogy advocates specific evidence of skills, knowledges, and identities that students consciously took up in a writing research course. This study also has the potential to deepen conversations about co-research as a writing research methodology and pedagogy. 


\section{CHAPTER I}

\section{WRITING RESEARCH PEDAGOGY GOES ONLINE:}

\section{A LITERATURE REVIEW}

Since one focus of this project is exploring ways that students take up writing researcher identities, the first portion of this literature review provides a context for the history and development of the writing research model for FYC. The second portion focuses on co-research, which serves as a primary methodology for the research in this project and provides a pedagogical approach to helping students attain the writing researcher identities valued in the writing research model. The final section reviews literature concerning online writing classrooms since this is the focus of the investigation the instructor and students took on together.

\section{Writing Research Model}

Writing research models for writing instruction have developed in response to newly evolving understandings of genre and activity over the past few decades. In light of these emerging theories, many scholars have recommended moving away from the traditional "general writing skills" FYC courses and towards a writing research framework that focuses on using flexible research skills to examine genres as complex actors in social settings (Russell, 1995; Smit, 2004; Downs \& Wardle, 2007). 


\section{Genres as Activity Mediators in Cultural Historical Contexts}

In her ground-breaking article "Genres as Social Action," Carolyn Miller (1984) describes genres as "typified rhetorical actions based in recurrent situations" (p. 159). Miller's definition identifies key characteristics of genres. First, genres emerge socially. The "recurrent situations" are social situations that have become normalized within a cultural context. Genres then become a means of facilitating certain social actions within those situations, and they become "typified" in that their form and structure evolve to better facilitate their associated social activities.

Catherine Schryer (1993) adds an important qualification to Miller's (1984) definition. She suggests that Miller's definition implies a stable system, and points out that "if genre is used to describe stable systems, then the concept is rhetorically unsound because a stable system cannot respond to changes in audience or circumstance" (p. 208). Thus, Schryer proposes the addendum that genres are a "stabilized-for-now or stabilizedenough site of social and ideological action" (p. 200). This theory suggests that genres do not retain the same form over time, but they instead evolve with the ever-changing societies in which they participate.

Understanding genres as "stable-for-now" social actors requires us to take a closer look at the cultural historical systems where genres participate. We can examine these systems through frameworks like actor network theory (ANT) (Latour, 1999; 2005), activity theory (Engeström, 1993), or cultural historical activity theory (CHAT) (Vygotsky, 1978; Prior, et. al., 2007). These theories suggest that our tools-whether they are texts, conceptual frameworks, or physical objects - participate as actors that mediate social activity. Latour (2005) gives the examples of "kettles 'boil[ing]' water, 
knifes 'cut[ting]' meat, baskets 'hold[ing]' provisions, [and] hammers 'hit[ting]' nails on the head" and poses the question, "Are those verbs not designating actions?" (p. 71). Latour (2005) does not suggest that "objects do things 'instead' of human actors" (p. 72). Rather, he suggests that a thorough understanding of social activities requires us to delineate all actor participants—-human and non-human—in the complex networks that mediate activity.

Genres, thus, mediate and sometimes remediate contextual social practices and knowledge. Prior, Hengst, Roozen, \& Shipka (2006) offer an example of mediation or remediation in citing a study of how psychologists convert patient talk into session notes and then eventually transform session notes into diagnosis codes that conform to the DSM-IV. Latour (1999) demonstrates how series of genres and multiple layers of remediation facilitate the production of knowledge. The scientists in his study used a particular device to extract the samples, they arranged the samples into a gridded box, they eventually transformed the box into a visual diagram on piece of paper, and so on until back in the lab and then the office, they eventually compiled type-written paper documents about their findings. The end result documents bore very little resemblance to the actual soil they represented, but as Latour (1999) writes, "In losing the forest, we win knowledge of it" (p. 33). Prior \& Hengst (2010) suggest that many activities use similar "multimodal chains of genres" (p. 8).

CHAT suggests that genres are both cultural and historical. Cultures develop tools to satisfy a perceived need or to facilitate a practice the culture considers valuable or necessary. Thus, "[t]hrough their designs, tools accumulate knowledge and perspectives that have situated perspectives" (Swarts, 2013, p. 152). As Latour (1999) reflects on his 
expedition in the Amazon, he writes, "Despite the pioneering quality of this expedition, it turns out, I am not assisting at the birth of a science ex nihilo" (32). Historical and culture practices informed the work that the scientists performed at each stage of the remediation process. The tools and genres that the scientists used were created in a particular culturalhistorical context in order to mediate activities that actors within that context-humans, political powers, cultural powers, etc. - deemed desirable. As Prior \& Hengst (2010) describe it, "[P]ast, present, and future shadow conversations suffuse the present" (p. 4). Shipka's (2011) discussion of remediation draws our attention back to Schryer's (1993) idea that genres and practices are only "stable-for-now." Over time, meditational tools and practices change. Shipka (2011) suggests that "mediated action is transformed by the introduction of new meditational means" (49). In other words, when tools evolve under new cultural-historical conditions, practices are remediated to adapt to the new tools. Though the objective of the activity system with the new tool might be the same, the manner in which the objective gets carried out may differ in slight or significant ways. Shipka (2011) offers the example of how students' composition practices changed when they moved from using typewriters to word processors. With word processors, writing multiple drafts or distributing several copies of a paper were more viable options because the remediated tool also remediated these practices, making them easier.

\section{The Myth of General Writing Skills}

In light of the research on genre theory, many scholars contend that the model of teaching "general writing skills" in FYC does not lead to transferrable skill development. Russell (1995) identifies "general writing skills" as the primary learning outcome for standard FYC courses. With activity theory in mind, Russell writes, "If writing were an 
autonomous skill generalizable to all activity systems that use writing, improving writing in general would be a clear object(ive) of an activity system. However, writing does not exist apart from its uses, for it is a tool for accomplishing object(ive)s beyond itself' ( $p$. 57). Russell compares teaching "general writing skills" to teaching general "ball handling” skills. Though many games use balls of various shapes and sizes (e.g., volleyball, football, croquet, jacks, etc.), the balls are used in very different ways. Russell notes that "A good croquet player might easily learn to putt, or a good tennis player learn squash. However, there is no autonomous, generalizable skill called ball using or ball handling that can be learned and then applied to all ball games" (p. 57).

Aviva Freedman (1993a) challenges the assumption that writing can be explicitly taught at all. She even suggests that explicit teaching can have an effect opposite the intention, namely, students might misapply the "rules" without regard to context. Students "may feel that they have learned something as a result of explication even though their later performance bears no evidence of that learning” (Freedman, 1993b, p. 274). Freedman (1993b) goes on to cite evidence that "there is little transfer between school and out-of-school tasks (p. 274). Like Russell (1995), Freedman (1993a) suggests that writing tasks are inseparable from their real world contexts. As Vygotsky's (1978) Zones of Proximal Development model suggests, "Full genre knowledge (in all its subtlety and complexity) only becomes available as a result of having written" (Freedman, 1993a, p. 236).

Empirical research supports the theories that students either fail to acquire and/or transfer the "general writing skills" into other contexts. Jarratt, Mack, Sartor, \& Watson (2009) interviewed 36 junior and senior university students about their memories of FYC. 
They found that students were divided in their feelings about the usefulness of FYC. Some participants felt they used knowledge from the course later on, some felt they did not, and others changed positions throughout the course of the interview. Bergmann $\&$ Zepernick (2007) conducted a study with students who complete a general FYC course and then three or four additional writing courses within their discipline. Their findings indicated that the majority of students did not remember FYC as useful because they did not use the same kinds of writing later on within their disciplines, and students also failed to recognize that writing was a process. The researchers recommended a shift in FYC courses from teaching students "how to write" and towards a focus on "teaching students how to learn to write" (Bergmann \& Zepernick, 2007, p. 141-2).

\section{Towards a Writing Research Model}

Bergmann \& Zepernick (2007) support Russell's (1995) move to situate writing instruction in the disciplines; however, the difficulty of finding faculty within the disciplines who can teach writing effectively and the added challenge of funding such a shift make the move unlikely for most universities. How then, might FYC programs make Bergmann \& Zepernick’s (2007) shift from teaching writing to teaching "how to learn how to write" (p. 141)? Wardle (2009) suggests that FYC courses cannot teach students to mimic disciplinary writing outside of disciplinary contexts. Like Bergmann \& Zepernick (2007), Wardle (2009) recommends leaving behind the notion that FYC can "teach students to write in the university" and instead taking up the idea of teaching "students about writing in the university" (p. 765). Just as biology, psychology, and other core curriculum courses introduce students to their own disciplinary subject matter, FYC might introduce students to scholarly writing studies. Students who develop a deeper 
understanding of how genres emanate from and facilitate activities in specific contexts can better understand how to examine and subsequently produce writing in new contexts. Illinois State University's (ISU) writing program takes Wardle's (2009) ideas a step further (Walker, 2014). While Wardle focuses primarily on writing about writing in university contexts, ISU's program encourages students to take up a diverse skill set that will enable them to examine literate activities in any context. Students take up the frameworks of genre studies and CHAT and then conduct multiple first-hand investigations of literate activity in a variety of contexts. Through these activities, students take up writing research skills, and they are encouraged to take up writing researcher identities (the sense that one is a person who is able to learn how literate activity works in a given context).

As ISU's program has evolved, further research has emphasized that to make a writing research model successful, students need to develop a robust understanding of their own uptake and transfer practices. Jarema's (2014) study of transfer between a writing research course and an Intro to Communications course indicates that unless students have a strong awareness of their own learning, they are unlikely to actively use high-road transfer (Perkins \& Salomon, 1988).

Although the term uptake has been used by multiple scholars in the genre and writing research fields (Freadman,1987; Kill, 2006), Bawarshi's (2010) research on the subject draws the most robust connections between uptake and transfer. Bawarshi suggests that uptake is a method for examining how we are learning and actively trying to transfer in antecedent knowledge to help us in new situations. In the context of a writing research based FYC course, teaching students to articulate their uptake may help them 
develop a deeper understanding of how to use uptake awareness to facilitate high-road transfer in new writing situations.

In light of the research on best practices in writing instruction, the course in this thesis study followed a writing research model. Besides introducing students to RGS and CHAT, the course encouraged students to examine their own uptake processes actively as they conducted real writing research and - to an extent - took up writing researcher identities.

\section{Co-Research Methodology}

To better understand how students take up writing research practices, this study employed a co-research model. Though the term co-research has not been used extensively in the literature, the methodology fits into a similar vein as methodologies such as participatory research, participatory action research, participatory design, and action research. These related methodologies have grown popular in fields like education (Glassman \& Erdem, 2014), social sciences (Fals-Borda \& Rahman, 1991), and technical communication (Salvo \& Ren, 2007; Spinuzzi, 2005; Grabill, 2007; Agboka, 2013).

\section{Participatory Methodologies}

Fals-Borda \& Rahman (1991) and Glassman \& Erdem (2014) concur that the

origins of participatory research are multiple but can largely be attributed to research with individuals in developing world nations in the 1970s. Fals-Borda \& Rahman (1991) emphasize that the primary foci of participatory action research (PAR) are empowering the oppressed and democraticizing knowledge production and use. Glassman \& Erdem (2014) note that contemporary uses of PAR draw from feminist methodologies and concepts of youth empowerment in education. Spinuzzi (2005) connects contemporary 
participatory design methodologies to action research; however, he points to origins in the collaborative design practices of Scandinavian researchers and trade union workers. Three key themes that surface in participatory methodologies include giving participants voice, valuing tacit knowledge, and viewing knowledge as socially constructed.

Giving participants voice and agency are essential to participatory methodologies (Spinuzzi, 2005). Salvo (2001) emphasizes that the participants are human beings, not means to an end in research or design. Both Salvo (2001) and Spinuzzi (2005) suggest a shift in the dynamic of researching about or for participants, advocating instead for researching with participants. Grabill (2007), for example, describes an action research study where the researchers worked with citizens in a community concerned about the environmental consequences of a dredging project proposed by the EPA. In the initial community meetings about the project, the citizens felt that the EPA and the Army Corps of Engineers dominated the conversation and did not allow the community members to voice their concerns. After hearing the community's complaints, Grabill's team worked to help the citizens change the interface of the meetings. Local citizens developed and distributed information packets prior to town meetings, which allowed a majority of the meeting to be spent in discussion. This format gave the citizens much more agency than the lecture-style meetings that gave voice to the "experts," but relegated the community members to a passive role. In short, Grabill's team worked with the community to identify their needs and to help them to actualize a solution that addressed those needs.

Valuing tacit, local, and embodied knowledges is fundamental to participatory methodologies and epistemologies. In their action research studies, Farkas (2013) and Grabill (2007) assert the value of frequently dismissed citizen knowledges. Farkas' 
(2013) work demonstrates that although citizens can access public discourse, the infrastructures do not always afford them agency to act on their knowledge. Grabill (2007), likewise, looks for ways to open infrastructures to influence from citizen knowledge, suggesting, "Citizens armed with both an understanding of the issues, as well as the local knowledge of how those issues will affect their community, can offer very valuable contributions to any decision" (Grabill, 2007, p. 13).

Spinuzzi (2005) describes participatory design as having a constructivist view of knowledge: "That is, it sees knowledge-making as occurring through the interaction among people, practices, and artifacts--knowledge doesn't just reside in the head; it's a condition of a certain context" (p. 165). Grabill's (2007) work supports this definition, and he uses it to explain the (im)balance of expertise, knowledge, and power in communities. He offers the example of a citizen who is familiar with the land (a type of metis) and notices a stream being polluted by a nearby manufacturer. The "expert" who inspects the problem declares that the pollution is not actually problematic because the stream is not on his map. The different communities of the two men hold different values, and they therefore privilege different information. Information and knowledge are, thus, not a matter of what is true but what is valued.

A participatory methodology is particularly appropriate for research in OWCs (Online Writing Courses) given their emphasis on participant voices, tacit knowledge, and socially constructed knowledge. An "expert" researcher may be able to make some sort of determination about what happened in an OWC based on an observational investigation. However, determining why or how literate activity happened in an OWC is practically impossible without involving the participants. While the computer screens 
render certain aspects of the course more visible (eg., discussions are archived), they

render other aspects of the course (e.g., the students' embodied experiences) as practically invisible.

\section{Participants as Researchers}

Though co-research has much in common with the participatory methodologies, its distinguishing characteristic is that it invites participants to conceive of themselves as researchers. Robin Boylorn (2008), who engaged Southern black women as coresearchers on a collaborative narrative project, defines co-research as "a participatory method that situates participants as joint contributors and investigators to the findings of a research project” (p. 600). In Boylorn's (2008) research, she actively involved her coresearchers in the processes of gathering, composing, and editing their narratives. While Boylorn did a majority of the writing for the final "product" of the research, she invited her co-researchers to provide feedback throughout the process. Liza Potts (2014) advocates for the distributed power dynamics visible in Boylorn's research:

We also must view participants as co-researchers and co-architects. . . . We must research with participants rather than be passive researchers commenting on their work. We must engage them in building and modifying these systems [social networks]. They deserve a seat at the table, a pen at the whiteboard, and access in ways that allow them to work across these ecosystems. (loc. 2450 of 3925 )

As Boylorn (2008) summarizes it, co-research is a shift from viewing participants as "researched" to "researchers."

Salvo \& Ren’s (2007) article “Participatory assessment: Negotiating engagement in a technical communication program" involves elements of both traditional participatory methodologies and co-research. In a similar vein as Grabill's (2007) work with community infrastructures, Salvo \& Ren (2007) characterize the "professional 
writing curriculum as a technology" (p. 425) and define students as key users or stakeholders. To tap into the students' knowledge of the program, they distributed surveys to both majors and non-majors in the department as well as conducting interviews and focus groups. The feature that I argue shifted Salvo \& Ren's (2007) research from participatory to "co-research" was their involvement of an undergraduate research assistant, who, among other things, conducted faculty interviews. Salvo \& Ren (2007) write, "As an undergraduate major, the research assistant acted as a participantobserver. Her role was complicated by the fact that she was herself a student and a member of the stakeholder group" (p. 430). Salvo \& Ren (2007) suggest that the position of their undergraduate research assistant helped them gain insights they would not have had access to otherwise. They write, "Rather than simply accepting administrative narratives describing the program, our assistant turned her research into an opportunity to articulate the relationships among stakeholders from her student perspective. And she ably articulated the student concerns" (p. 431).

\section{Co-research as Pedagogy}

Like research, pedagogy is concerned with issues of knowledge-making. Salvo (2001) writes, "Participatory design seeks to establish democratic workplaces where users are recognized as experts in their job while the expertise of designers is seen as a separate but equal expert knowledge" (p. 273). If we apply a similar mindset to the classroom, we can come to a place where we value students' and instructors' knowledges equally.

In light of all the research that suggests that learners make meaning in situated social contexts (e.g., Vygotsky, 1978; Freeman, 1993a), co-research might serve as an appropriate model for helping students take up writing research practices. Freedman 
(1993b) emphasizes that "[a]11 learning is necessarily situated within a community of practice in which learners are enabled to perform by an intricately orchestrated process of co-participation with old-time members" (p. 275). Classroom co-research has the potential to benefit both students and instructors. Researchers, particularly teacher researchers, can benefit from student voices and the perspectives they offer for both theory and practice (Nickoson, 2012). Student co-researchers, likewise, take on additional agency in the processes and outcomes that ultimately impact them and their peers. Additionally, student co-researchers have the potential to acquire deeper knowledge of research practices and may even have the opportunity to contribute to professional knowledge.

Smart and Brown's (2008) participatory action classroom study uses most aspects of co-research. The researchers trained 36 student interns to do self-reflexive ethnographic research of their workplace environments. They then talked through the students' findings at weekly classes and explored ways that the students could be agents of change in their workplaces. These changes might come through the students doing more research and modifying their own behaviors or the students advocating for changes in the organization. Although this study fits most aspects of a co-research model, Smart and Brown did not encourage participants to conceive of themselves as researchers. From a pedagogical perspective, encouraging students to take up researcher identities might help them embody and transfer writing research skills.

Co-research and other participatory or action research methodologies have the additional potential to build learners into more active citizens. Farkas (2011) argues that writing instructors have a responsibility to prepare students to engage in their 
communities. She assigns projects that encourage students to research and take action about an issue of concern to them in their communities. Salvo \& Ren (2007) argue that engaging students in decision making about institutional practices better prepares them to become actively engaged citizens in their communities and other institutions after they leave the university.

From both a methodological and pedagogical perspective, I would argue that a coresearch model also has the potential to increase student investment in the investigation. In a chapter on using wikis in a course, Dolmage (2012) reflects on surveys he collected from his students participants, saying, "Many of the student responses were generic and evaluative - the wiki was good, or it was bad, and little explanation was offered" (p. 124). I bring up this quote precisely because it is not representative of the work my student co-researchers produced as part of this study. In past investigations where I used a more traditional researcher/participant model, I received the same sort of perfunctory responses that Dolmage describes. However, because my students in this thesis study were invested as researchers, I believe the need to produce substantial and usable data was as meaningful to them as it was to me.

\section{Limitations of Co-Research}

As with any methodology or pedagogy, co-research has certain limitations. Blythe, Grabill, \& Simmons (2008), among others, assert that participatory methods should allow researchers and participants to share equally the responsibilities of selecting research questions, methods, analysis, and reporting. However, a truly equal division of power and labor may not always be attainable. In a classroom situation, the instructor 
automatically has certain power and authority over the students by virtue of his or her control of grades, course policies, etc.

Spinuzzi (2005) notes several limitations of participatory design, many of which also apply to co-research. For one, co-research requires a significant amount of time. For this thesis project, for example, the co-research project took up almost half of the ENG 101 course. Spinuzzi (2005) also notes that participants/co-researchers may not have formal training or experience in research methods, so their execution of those methods may not be exhaustive.

\section{Constructing Knowledge in Online Writing Courses}

For this thesis study, an online writing research course served as the site of a student and teacher co-research investigation. Thus, the function of this next section is twofold. First, it provides a partial rationale for the design of the course where the research took place. (The course itself is described in more detail in Chapter 2). Second, this selected and brief overview of the literature on online writing courses serves as a backdrop for the student co-researcher's investigations (which are explored in depth in Chapter 3). Though most of the student did not engage heavily in the literature themselves, their choice of investigations dealt with issues of self-representation online, the affordances and limitations of the LMS (learning management system), peer review, and knowledge uptake and construction.

\section{Towards Constructivist View of Learning and Knowledge}

Many composition researchers claim that OWI (online writing instruction) frequently follows what DePew \& Lettner-Rust (2009) refer to as "banking" pedagogies, where the instructor "deposits" a wealth of knowledge in the students' impoverished 
minds (c.f., Warnock, 2009; Gillam \& Wooden, 2013; Remley, 2014). Gillam \& Wooden (2013) point out that the LMSs for online courses often encourage this teacher-centered model; however, they also note that most LMSs include collaborative platforms that sometimes simply go unused.

Despite the prevalence of teacher-centered OWI, the Conference on College Composition and Communication (CCCC) Committee for Best Practices in Online Writing Instruction (2013) urges that instructors take up learner-centered pedagogies. Most current theory about e-learning recommends using a social-constructivist model (e.g., Warnock, 2009; Pachler \& Daly, 2011; Swenson \& Taylor, 2012). As Pachler \& Daly (2011) describe it, learning is not about "individual cognition alone, but is a process of engaging in the social world and mediating the sense that is made of it through some form of sign which is communicated to others and around which shared meanings can be forged" (p.62).

Constructivist and learner-centered OWI recognize the knowledges and perspectives of both instructors and students as valuable. DePew \& Lettner-Rust (2009) suggest that moving from "banking" style of teaching to a student-centered style "is not just a shift in epistemological philosophy and pedagogy. It is a shift in power; it is a shift in the way one articulates who gets to contribute knowledge in the course" (p. 175). Swenson \& Taylor (2012) claim that discussion boards and other online collaboration tools can promote this distribution of power because they encourage instructors to move from the central role of knowledge disseminators to more of a peripheral role as learning facilitators. The distinct roles of student and teacher can blur in online writing classrooms if instructors "are willing to concede absolute authority and give students the opportunity 
to explain how they are engaging with the course material"' (DePew \& Lettner-Rust, 2009, p. 177). Ruey's (2010) study of OWI supports this idea as both students and instructors reported learning from one another's perspectives.

Gillam \& Wooden (2013) seem to suggest that valuing students' knowledges can help them practice transfer between environments. They encourage helping students to recognize "not that they know nothing but that what they know is situated — negotiated, even - between a variety of distributed sources, students begin to understand that their knowledge might alter its situation if they distribute their learning across a wider spectrum" (Gillam \& Wooden, 2013, p. 30). Anthropologists Andrews \& Varenne (2011) affirm that students' prior knowledges are essential to their participation in technologymediated courses. Studying blog comments, they found that students using educational technology largely acquire those technologies outside of educational settings.

Furthermore, this acquisition happens socially rather than as a direct dissemination of information between expert and novice. As Andrews \& Varenne (2011) write, "Everyday life is not divided between those who know and those who do not; it is not united by the sharing of old knowledge" (p. 8). Rather they argue that knowledge is constructed.

\section{Mediated Spaces}

Warnock (2009) suggests that our "goal is to get past the technology and start thinking about teaching" (p.22). The CCCC (2013) supports this idea, urging that technology should never be the central focus of OWI. However, as Brown (2006) writes, "An ecological view of writing asks writing teachers and instructors to locate themselves within [activity] systems and, at the very least, to create an awareness of the various systems that make up the social world relevant to particular acts of writing" (p. 11). Van 
Ittersum \& Lawson Ching (2013) echo this refrain when they assert that "the 'writing process' is not so much a static cognitive structure as it is a set of complex interactions among writers, their tools, and their objectives" (n.p.). Any robust theory of online education must account for how various tools function as actors that mediate (and sometimes impede) activity in our classrooms.

One of the most influential non-human actors in OWI is simply alphabetic text. Pachler \& Daly emphasize the primacy of language and discourse in mediating knowledge production in social contexts in general, but suggest that text becomes especially essential in online spaces. Griffin \& Minter (2013) highlight just how text-rich online classrooms are when they share that "the reading load in online classes was more than 2.75 times greater than" that of traditional classes (p. 153).

Simply noting that written text replaces corresponding voiced or gestured language in face-to-face classrooms does not fully capture the work that text does in an online environment. In distance learning interfaces (including but not limited to online courses), text functions as a vicarious bodily presence for participants. Brown (2006) suggests that online learners "[take] on the characteristics of metonymy and synecdoche, reducing opportunities for online groups to enact different forms of representation" (p. 9). Online students are not simply composing writing; they are composing themselves. Drawing on the example of correspondence courses, DePew \& Lettner-Rust (2009) somewhat ominously point out that "the students are merely disembodied words instructors receive in correspondence. ... [S]tudents embody their errors" (p. 179).

Considering the mediated relationship between texts and bodies is particularly important in OWCs that embrace a constructivist pedagogy because such courses 
(should) value students' embodied knowledges. Gillam \& Wooden (2013) remind us that

"students are not actually disembodied just because we may never see them--but their embodied selves have become separable from the processes of learning and writing, disembodying our learning spaces if not our learners, and discouraging us all from seeing knowledge production as having a material, bodily component" (p. 29). If we want students to critically examine how their knowledge production happens, we need to encourage them to consider both their embodied processes and the mediating tools that allow them to represent that learning in the online classroom. Van Ittersum \& Lawson Ching (2013) recommend encouraging students to select and shape their own digital environments within courses so they can develop a better understanding of the mediating tools that impact their composing processes and allow or impede their representations of themselves.

\section{Limitations of Constructivism in OWCs}

Although a significant body of research supports the use of constructivist pedagogies in OWC, we must examine the limitations of these models if we are to continue to refine them. Rendahl \& Breuch (2013) claim that their study of FYC online writing students indicates that students did not consider peer interactions important to their learning, citing data that suggests that most students rarely or never opted to communicate with other students in a class chat room. They hypothesize a number of factors that may have led to students' low value of peer learning. Students may have only exerted minimal effort on the peer review tasks, or perhaps they underestimated the value of those interactions. However, Rendahl \& Breuch (2013) also suggest that the findings may highlight flaws in constructivist approaches to writing instruction online. Effective 
social knowledge production requires a particular cultural mindset that students may or may not have been exposed to prior to their OWC. A single instructor may be limited in how much they can help students acknowledge the value of peer input rather than simply viewing their teacher as the focal knowledge-keeper in the class.

A purely social-constructivist model may also fail to account for diverse cultural factors that influence knowledge making. Advocating for a cultural studies model, technical communicators Scott, Longo, \& Wills (2007) claim that social-constructivism "avoids questions about the politics of knowledge legitimation and power" (p. 12). As an example, Longo (2007) cites the work of Stephen Doheny-Farina, saying that the study does well to situate technologies in a social context but that it fails to consider cultural influences beyond the organization that impact the technologies' uses. Although the CCCC (2013) OWI Position Statement's primary objective is to promote accessibility and inclusivity in OWCs, their recommendation to base OWI documents on "plain language" principles may not account for the situated cultural needs of all classes. Although a robust examination of culture is outside the scope of this thesis study, future researchers should examine the cultural factors that impact social knowledge construction.

A final issue that may impede social constructivist pedagogies in OWCs is students' disparate access to technologies prior to the course. Sherblom, Withers, \& Leonard (2013) found that in computer-mediated discussions, students' familiarity with the medium they were using to communicate was the strongest predictor of the strength of their discussions. Students who lack technology exposure prior to the course may find that the technology impedes their ability to make knowledge, whereas in another 
interface, they could work productively. This suggests that our current OWC technologies are yet insufficient to allow universal access and usability.

\section{Setting the Stage}

Since the field still has much to learn about writing research pedagogies, coresearch methodologies, and best practices for OWCs, this study sought to add to the empirical research related to these areas. In the course design described in Chapter 2, you will see the application of the writing research model and OWC principles discussed in this chapter. The structure of the study (also described in Chapter 2) draws on a coresearch methodology in order to A) provide a more thorough and democratic investigation of the OWC by involving the students as researchers and B) offer greater insight into the students' perceptions and demonstrations of their writing researcher identities. The results of these two goals are explored in Chapters 3 and 4 respectively. 
CHAPTER II

\section{STUDENTS AS RESEARCHERS: METHODOLOGY}

\section{AND METHODS}

This study uses a co-research model to explore the literate activity and student uptake of writing researcher identities in an online Composition as Critical Inquiry (ENG 101) course. As discussed in the literature review, co-research is a type of participatory research that invites participants to conceive of themselves as researchers (Boylorn, 2007). The goal behind using a participatory methodology was to afford students more agency in the research process; however, the hope was also that using a co-research model specifically might encourage the students to conceive of themselves as writing researchers.

Since the course was an experimental implementation of the ENG 101 course in an online environment, the course itself served as the site of inquiry for the co-research investigation. Selecting the course as the setting for and object of our research satisfied a number of exigencies. First, the researchers (students and instructor alike) would already be familiar with the course setting. Selecting a site of inquiry outside of our course (e.g., if we were to all work together to study literate activity at the campus library or on a particular social media site) might have meant that some students were more familiar with the setting than were others. Second, our course offered a very narrow site of inquiry 
while still allowing the student co-researchers to select widely divergent paths for their research to follow. A narrow site of inquiry (as opposed to broader topics like "online courses in general") would also encourage students to take up and perform primary research methods. Third, the university's Writing Program was already interested in collecting research on the implementation of the ENG 101 course in an online environment. Thus, the real world implications of the student co-researchers' work could potentially extend beyond our classroom.

With these ideas in mind, two primary questions guided this research:

- Question 1: How does literate activity occur in an online Composition as Critical Inquiry course?

- Question 2: What writing research skills, knowledges, and/or identities did students take up and demonstrate as they participated in a co-research project?

I, the instructor of the course, and the student co-researchers worked together to answer the first question through a series of student-directed studies in the ENG 101 course. For the second question, I worked with a focus group of students from the course to define writing research skills and knowledeges and explore the extent to which the students consciously took up writing researcher identities. I describe the specific methods for each of these components of the study in greater detail later in the chapter.

The design of this study also draws our attention to questions about the efficacy of the co-research model itself. Question 1 allows us to examine co-research as a methodology while Question 2 encourages us to evaluate its pedagogical potential.

\section{The Course}

Before exploring the specific methods used in this study, this next section offers a detailed description of the course that served as the site of inquiry for the study. I begin by offering a brief rationale for the course, discussing how it follows a Writing Research 
approach to FYC and how it employs social constructivist pedagogies in an online environment. Next, I provide details on the actual projects and procedures we used in the course.

\section{Rationale for the Course Design}

Based on research on genres and activity (Russell, 1995; Miller, 1984; Freedman, 1993a; Freedman, 1993b), this ENG 101 course operated on the understanding that the most transferrable skill we could teach in FYC was not how to write but how to research how to write (Downs \& Wardle, 2007; Walker, 2014). To that end, this course sought to equip students with basic knowledge of genres and their development and functions within cultural-historical activity systems. Additionally, the class aimed to help students develop and/or deepen a repertoire of research strategies that would allow them to analyze, produce, and interrogate genres in specific contexts.

The course design also aligned with social-constructivist views of knowledge production (e.g., Vygotsky, yr; DePew \& Lettner-Rust, 2009), while attending to both the affordances and challenges of realizing such a pedagogy in an online environment (e.g., Gillam \& Wooden, 2013; Pachler \& Daly, 2011; Warnock, 2009). The structure of the course sought to affirm and value students' prior knowledges and experiences and provide avenues for students to share those knowledges with the learning community. Using collaborative features on the LMS, the students engaged one another in discussion on a regular basis. Students took part in both large group and small group activities. The small groups had the same 3-5 students throughout the semester to encourage students to develop relationships, which is often a challenge in online environments. To help students value these peer interactions, I based nearly a third of their grade on the quality 
of their participation in the weekly discussions and small group activities (c.f., Warnock, 2009). By comparison, a mere $5 \%$ of their grade was dedicated to traditional comprehension assessments of assigned readings/viewings. As a bridge into understanding activity and genres, the first two weeks of the course also encouraged students to think critically about the technologically mediated nature of our course (c.f., Van Ittersum \& Lawson Ching, 2013).

\section{Course Structure}

The course in was an entirely online and asynchronous section of ENG 101: Composition as Critical Inquiry. It was a 16-week required general education course worth three credit hours. Twenty-three students initially enrolled in the course, but two dropped the course early on leaving us with twenty-one students for the majority of the semester.

Two primary platforms were used to facilitate the course work: ReggieNet and GoogleDrive. ReggieNet was used for the gradebook, blogs, discussion forums, quizzes, and final project submissions. GoogleDrive housed the weekly schedule, readings, assignment descriptions, and various folders for small group activities.

In a typical week, students were expected to complete the required readings and video viewings by Tuesday at midnight and take a brief comprehension quiz over the content. By Thursday of each week, students were to submit their "primary" posts on all relevant discussion forums or small group exercises (depending on which was assigned that week). The forum discussions were open to the entire class while small group discussions/activities involved consistent groups of 3-5 students throughout the semester. On Fridays, students were to post at least two "secondary" or "response" posts per 
primary post (e.g., on a week where three primary posts were assigned, students would need to post six secondary/response posts) (c.f., Warnock, 2009). All posts were graded based on quality. Students were also expected to post an uptake blog by Saturday at noon. In these blogs students reflected on how they had learned throughout the week. As the students often struggled to take up the concept of uptake (particularly early in the semester), I often provided guiding question such as the following ${ }^{1}$ :

- What prior knowledge did you transfer in this week?

- What problems did you encounter as you worked this week? How did you solve them?

- What ideas or processes from this week might be useful to you in specific future situations?

As an instructor, I also participated in the discussions and small group exercises. To allow students maximum time to express and explore their own ideas and insights, I always waited until after the second round of posts to begin commenting. When possible, I made an intentional effort to affirm the comments of students' peers to help them develop a sense of authority in their discussions and feedback. In addition to the feedback I provided on the forums / Google docs, I also sent the class a weekly 5-10 minute “check-up-date" video where I provided updates, generalized class feedback, and usually concluded with some recent anecdote from my life. I felt that these videos allowed me to assert a greater sense of presence and approachability, which was important to me because I believe that students can easily feel isolated in an online environment. The students were not required to watch these videos, but many said they did.

\footnotetext{
${ }^{1}$ Appendix A provides a more detailed description of the Uptake Blog Assignment.
} 
In an effort to encourage peer learning, I also promoted a “Don’t keep your eyes on your own paper" course policy. Save for final project submissions, all student assignments were posted publically (to the class), and I encouraged students to "peek" at one another's work. I merely asked students to mention or credit any peers who influenced their ideas as a professional courtesy. While some instructors fear that such a policy might invite plagiarism, I have had no issues with this setup in any class I have taught at the college level as long as the assignments required significant individualization.

The course focused on helping students develop writing research skills. Students were introduced to uptake, genre studies, and cultural historical activity theory (CHAT) ${ }^{2}$ as guiding theories to facilitate their work. For the first six weeks, the course focused on helping students cultivate an understanding of these concepts through videos, activities, and readings, particularly readings from the Grassroots Writing Research Journal $(\underline{G W R J})$.

The GWRJ publishes original research articles about literate activity in a variety of contexts, and it considers undergraduate researchers one of its primary audiences. Although the journal served as our primary text for the course, I discussed key differences between textbooks and journals with the students during the first few weeks of the course. I asked the students to engage with the journal as researchers, encouraging them to examine the authors' methods, question the studies, look for ways to expand on

\footnotetext{
${ }^{2}$ Appendix B provides excerpts from the glossary of key terms used during the course. The glossary comes from my article in the 5.1 edition of the Grassroots Writing Research Journal, which the students read during week 3 of the course. This excerpt provides basic definitions for antecedent genres, CHAT, genres, and uptake.
} 
the studies, and consider how the studies in the journal fit into or conflicted with the students' own research interests.

Following the introductory weeks, we spent 2-3 weeks on our first major project - an exploration and production in a genre of each students' choice. For the second major project, we spent the remaining 6-7 weeks of the semester conducting primary research investigations of how literate activity occurred in our course during the first half of the class. The project culminated with each student writing or co-authoring an article for the $G W R J^{3}$. In the early parts of the project, students completed a genre analysis $^{4}$ of the $G W R J$, reviewed primary research strategies and completed CITI training on low-risk studies involving human subjects. Next, we brainstormed a list of possible research questions in a collaborative Google Doc. Each student then met individually with me (face-to-face) to select a research question that suited their interests and to discuss possible research strategies that might help them answer that question. I required students to use at least three different research strategies that may have included but were not necessarily limited to secondary research, interviews, surveys, textual analysis, and (auto)ethnography. The students then wrote out their research procedure plans along with modified informed consent documents as appropriate, which went under both instructor and peer review. Following the completion of data collection, students wrote up short research reports ${ }^{5}$ summarizing their methods, analysis, findings, and general experience with the process. During this time, students were also asked to view several videos on data analysis methods, including a screen capture video where I showed them examples

\footnotetext{
${ }^{3}$ Students were not required to submit their articles to the journal, though some did choose to do so at the conclusion of the semester.

${ }^{4}$ Appendix $\mathrm{C}$ includes the genre analysis assignment.

${ }^{5}$ Appendix D includes the research report assignment.
} 
of analysis techniques I had used in some of my own research experiences. For the final step in the project, students wrote (or co-wrote) an article about their research for the GWRJ. Peer/instructor review and revisions happened throughout the project process.

\section{Question 1 Methods}

To answer Question 1, my co-researchers and I used the following methods. As described in a previous section, each student completed a primary research investigation about a specific aspect of the literate activity in the course that suited their interests. To maximize the students' opportunities to publish or present their research findings, we obtained IRB approval through batch protocol 2014-0310. The IRB also approved protocol 2014-0311 for this thesis project.

Students were informed about the research being conducted for this thesis project at the beginning of the second project in the course; however, students were not invited to participate in the research until the end of the semester. All of the students' activities up until this point were part of their normal, required coursework. By waiting until the conclusion of the project to invite students to participate in the project, participants had better knowledge of the materials they actually produced (as opposed to asking them to participate before they had actually produced anything). Because I was the instructor of the course, I did not learn the identities of participating students until after I had submitted final grades in order to avoid the risk of coercion. Since it was possible that a non-participating student might have participated in a participating student's in-class research project, the informed consent document contained multiple layers of consent. Students were asked to specify if they would allow each of the following types of documents to be included in the study: 
- Materials they produced

- Materials produced by others that involved them as participants (e.g., interviews with them, research materials where their work was considered as a writing sample, etc.)

Because the research design invited students to be active agents in the research process, participants were also given the option of having their identities kept confidential or to be added to protocol 2014-0311 as co-principal investigators. Additionally, students were asked to specify if they were willing to be contacted for an interview at the beginning of the 2015 Spring semester. Once data was collected, identifying information from students who did not wish to be named was removed or rendered anonymous.

Even though participation did not require any additional effort on the part of the students (unless they opted to be interviewed), I was only able to recruit seven participants from the class of twenty-one students. Although I maintained good rapport with the class on the whole, the low level of participation is likely an effect of the online course environment and the timing of the recruitment. Two of the three recruitment emails were sent out during students' exam week or during winter break. As emails, the recruitment invitations may have been easy to overlook.

To better understand the writing that happened in the course, I created an overview of the student co-researchers' findings. I treated their final articles as scholarly literature and compiled the findings in Chapter 3 of this thesis. Following each article summary, I evaluated the affordances and limitations of the findings. At the end of the chapter, I included a synthesis of the overall findings from the co-research investigation followed by a discussion of the efficacy of co-research as a methodology. 


\section{Question 2 Methods}

In January of 2015, I met with Mark Hoffman, Claire McCrery, Joe Riggs, and Samantha ("Sam") Woods for a one-hour focus group to discuss the students' perceived uptake of writing research skills, knowledges, and identities. Prior to the session, I reviewed informed consent documents with each participant. Beyond the usual information on the study, the consent documents also invited the participants to clarify if they wished to be added to the study as named co-researchers. All four students elected to serve as named co-researchers.

We were about a month into the Spring semester, and three of the four students (Mark, Claire, and Sam) were enrolled in Introduction to Communications, COM 110, the partner class with ENG 101. Since some time had passed since we had completed the course, I provided each group member with a copy of their final blog from the class, which asked them to reflect on their understanding of being a writing researcher. This document was intended to serve as a refresher, but most of the students did not look very closely at it.

For the first half of the session, I asked the group members to identify the knowledges and skills they considered essential to being a writing researcher. We defined knowledges as "things you know how to think about" and skills as "things you know how to do." However, as we worked, we found that the terms were not entirely discrete since certain types of thinking are also skills, so we eventually ignored the distinction between the categories.

Although I made a distinct effort to afford the student co-researchers maximum agency in the focus group, I feel it important to include some notes here on my role in the 
discussion. As the former instructor, I automatically assumed the centralized role of authority. Particularly since the students (with the exception of Claire and Sam) had never met each other in person, I played a central role in keeping the discussion flowing. I had recently re-read a lot of the students' work, so I frequently referred to specific instances in their Grassroots articles or blogs as a means of both legitimizing their work in that space and inviting them to reflect further on what they had done. We met in a room with a whiteboard so we could record the list of skills and knowledges visually. I invited the students to write on the board, but when no one volunteered, I asked if they would prefer for me to act as the recorder instead. Throughout the discussion, I asked clarifying questions, supplied examples from my experience as both a writing researcher and an instructor, and suggested possible terms to describe the concepts students were discussing. I avoided generating my own direct contributions to our skills and knowledges list because I was more interested in seeing what the students consciously took up than checking to see if they took up what I tried to teach them. At one point, however, Mark directly asked me what I considered the most important writing research skill. I said, "Being able to identify what you don't know," but I asked the students to corroborate the idea with their own experiences before I added it to the list.

During the second half of the focus group, I asked students to reflect on their identity as writing researchers both during the class and at the time of the group-about two months after the class. I prefaced the question by describing an experience I had as a senior in high school. My English teacher tried to encourage my classmates and me to think of ourselves as writers, which in hindsight, might have been an effort to help us taking up writer identities. At the time, however, I remember thinking that calling myself 
a "writer" seemed silly to me even though I did a great deal of writing for school, leisure (I was working on a novel at the time), and work (I wrote articles for my small town's weekly newspaper). I told the students that, at least in my view, having a writing researcher identity was not about going around and calling themselves writing researchers; instead, I encouraged them to think of having a writing researcher identity as being a person who believed they could perform the thought processes and skills we had just listed on the board.

\section{Coding for Writing Researcher Skills and Knowledge}

Following the focus group, I transcribed the digital recording of the discussion and selected a set of documents from the students' work to code using the list of terms that the students generated during the focus group. I coded a total of 65 documents, which included the students' uptake blogs (13 - 15 entries per students), the students' GWRJ genre analyses, the research reports, and the focus group transcription. I used the weekly blogs because they captured a series of snapshots of each students' thinking throughout the semester. The GWRJ genre analyses and research reports were scaffolding assignments that helped the students work towards writing their GWRJ articles; as such, these assignments captured a lot of the students' thought processes about the co-research project in particular.

As I reviewed the list of codes from the focus group session, I merged a few similar terms into single codes (e.g., SELF-ANALYSIS / INTROSPECTION). I also opted not to code for a few of the terms the students generated, namely CREATIVITY, CRITICAL THINKING, and OPEN-MINDEDNESS. These concepts were so broad that 
I did not feel I could accurately or productively code for them. Figure 1 contains the original list of codes from the focus group.

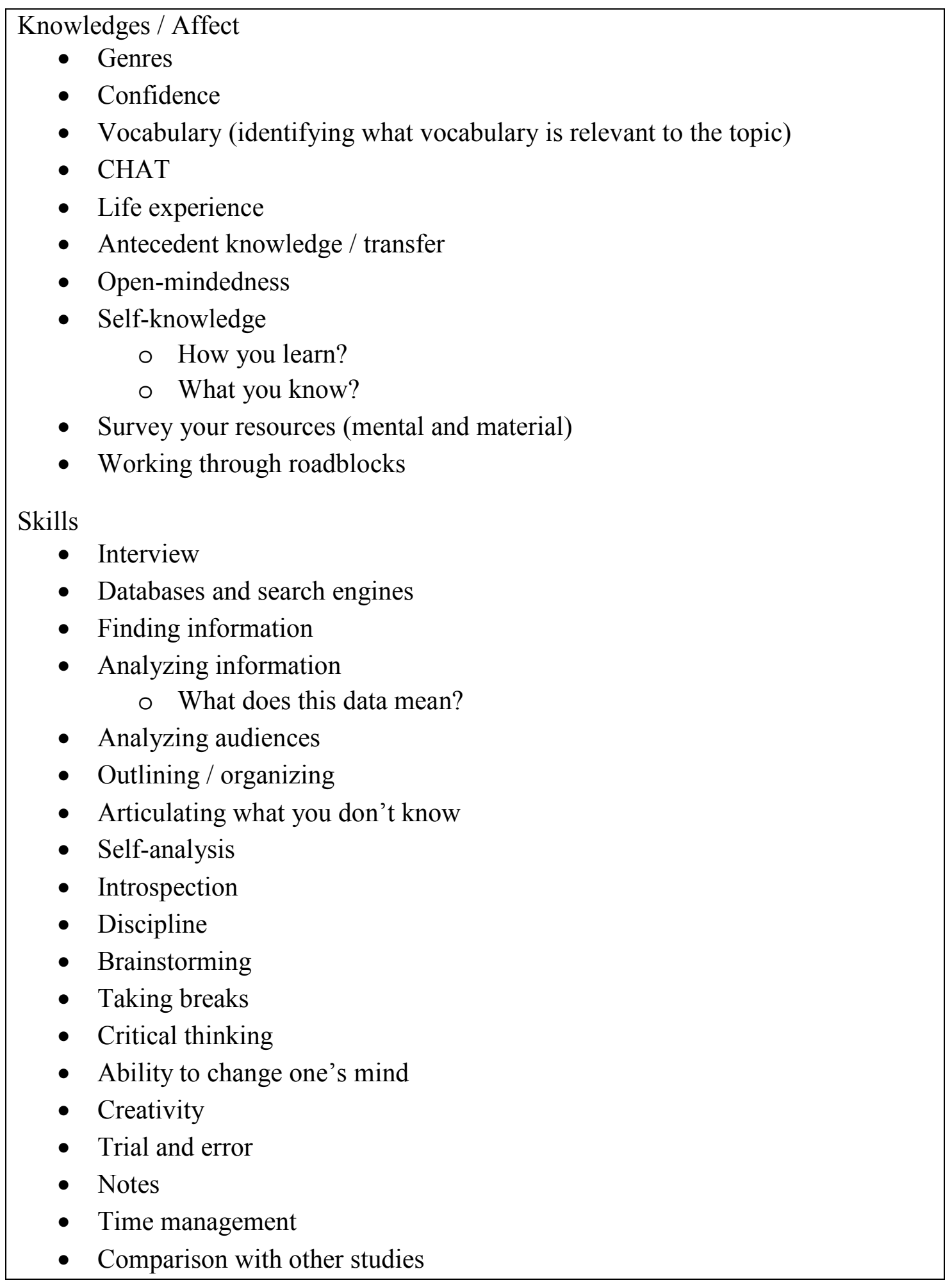


- People skills / recruiting

- Survey

Figure 1. Student generated list of skills and knowledges

During the coding process, I also generated four additional codes that the students did not name on their list. I added these codes with the following justifications:

- OBSERVATION: The students listed discussed self-observation / autoethnography during the focus group, so I felt that coding for third-person observation was also appropriate.

- TECHNOLOGY AWARENESS: The students brought up some interesting comments on the influence of non-human actors on their thinking processes, so I opted to code for their explicit discussions of technologies and tools in a broadly understood manner (e.g., not limited to digital technologies). I also thought this a relevant code since the course was online.

- FORWARD-REACHING TRANSFER: I added this code as a counterpoint to the student-generated code of ANTECEDENT GENRE / EXPERIENCE

TRANSFER. Depending on the timing of the discussion, the distinction between backwards-reaching transfer and forward-reaching transfer was unclear.

- INFORMAL RESEARCH: During our conversation about writing researcher identities, I noticed the students focusing primarily on FORMAL RESEARCH contexts and practices (e.g., writing papers, speeches, etc.). When I asked them about their use of informal research in the focus group, they struggled to articulate it, so I wanted to see if this struggle was consistent with their work from the semester.

Besides the four codes listed above, I opted to work from the student-generated code list for two primary reasons. First, the student list allows us to understand better how this group of students conceptualized writing researcher identities. What the instructor wants students to take up vs. what the students actually take up may differ, and in studying issues of identity, the students' actual uptake is probably more interesting than instructor's desired learning outcomes. Secondly, using the student list to code the students' work allowed me to compare the skills and knowledges the students perceived 
themselves as taking up to their actual demonstrations / performances of those skills and knowledges in the context of the course assignments.

The results and discussion of this portion of the study are detailed in chapter 4.

\section{Meet the Researchers}

Having discussed what we did in this project, I would like to take the opportunity to talk about who did it - the participants and co-researchers themselves. Adela, Wes, and Katie $^{6}$ willingly shared their research from the course in our collective effort to answer the first research question. Mark Hoffman, Claire McCrery, Joe Riggs and Samantha "Sam" Woods participated in the focus group in addition to sharing their work from the class. These four were invited - and all consented - to act as named co-researchers on the project. Below, I share a bit about each researcher's major, activities in the course, and first and second course project. Although the first class project was not the primary focus of this study, the students had such a high degree of choice on this project that I feel it illustrates some of their writing research interests.

\section{Adela}

Adela was a freshman music major with aspirations for being a music therapist.

During the course, she frequently brought her musical interests and genre awareness to bear on our conversations (music was an area of shared interest for many of the students in the course). For her first course project, she created a mellophone audition video for the Blue Stars Drum Corps. Throughout the course, she was an active participant, often leaving more comments than were required. Adela was part of a fairly active peer small group on Google Drive (along with Mark), which perhaps influenced her decision to

\footnotetext{
${ }^{6}$ These three participants are listed as pseudonyms.
} 
study the differences in communications on ReggieNet and Google Drive for her second major project.

\section{Wes}

As a freshman nursing major, Wes was assigned to the small group that I called the "So you're going into medicine" group. He along with a few others from his group opted to create medical treatment plans for their first project. Wes was a constructive peer reviewer, and as his research (an investigation on what led to quality peer review in our course) illustrates, he found the peer review experience very productive in the course. I frequently referred other students to Wes's work as an example when they seemed to be struggling on a particular assignment. He was particularly adept at articulating his uptake throughout the course. At the conclusion of the course, Wes reported that he did submit his Grassroots article to the journal for possible publication.

\section{Katie}

A freshman fashion major, Katie created a fashion blog entry for her first project. Like Wes, Katie was particularly adept at articulating her own uptake, and I frequently referred other students to her blog as an example of what uptake-type conversations looked like. Katie's execution of her genre productions was not always on target, but for the most part, she was able to articulate the areas of mis-match between genre conventions and her product. For her second project, Katie examined how our online course allowed students to represent themselves differently than did face-to-face courses.

\section{Claire}

Claire started out the course as a psychology major, but told me during the focus group that she was switching her major to business. Though she initially struggled to 
identify a focus for her first class project, she ultimately created a how-to guide on instructibles.com for playing the major chords on a piano. Since this was one of the most public projects in the class, Claire was able to reflect on the audience reactions of realworld users who commented on her instruction guide. Claire kept a detailed uptake blog, frequently noting how the new information in the class differed from the content and systems she had used in high school. Claire partnered with Sam on her second project to explore how/why introverted students felt more comfortable in the online course.

Joe

An aspiring dentist, Joe was with Wes in the "So you want to go into medicine" group. As with Wes and Katie, I frequently referred other students to Joe's work as a positive example. Joe faced some challenges as he created his first project-an online advice column—but he adeptly articulated the ways that his process in producing the blog did not conform to typical genre conventions. Like Wes, Joe was also a very helpful peer reviewer (which, perhaps, contributed to the positive environment that helped Wes develop his article). I strongly encouraged Joe to submit his Grassroots article at the end of the semester, and he let me know that he did so.

\section{Mark}

One of the two "non-traditional" students in the course, Mark was a part-time student in his 30s with three children. Although he had not yet declared a major, he was leaning towards journalism. Mark took to the concept of uptake very quickly, which we discussed might have been because he so frequently sees his children engaging in the learning process in his everyday experience. For his first class project, Mark chose to write a letter to his deceased father. One thing that particularly impressed me about this 
project was how he ably and critically articulated the different audiences that might interact with his production. Mark was by far one of the most active participants in the course, leaving plenty of constructive and encouraging feedback for his peers. For his second project, Mark tried to study our class's uptake of uptake. While his process materials such as the Research Reports were very thorough and demonstrated strong analytical skills, his final article missed the mark, which he adeptly identified and discussed in his Genre Analysis.

Sam

A freshman psychology major, Sam was in the same small group as Katie and Claire. For her first project, Sam created a YouTube guitar demo of a popular song that was very genre-appropriate. Sam's uptake blogs were not usually very lengthy, and while there was no specific length requirement, she did not always achieve a robust level of detail in that space. In contrast, her genre analyses were fairly articulate, and I found her contributions in the focus group particularly insightful. As I mentioned above, Sam worked with Claire on project 2. I offered to allow any of the students in the course to work together, but Sam and Claire were the only two that ultimately decided to do so. The two expressed that this project was one of the most successful and positive collaborative endeavors that they had ever undertaken.

\section{Myself}

As this is a co-research project, I feel it appropriate to identify my subjectivities and positions in the project as well. I taught this course in my fourth year of teaching, but it was my first time teaching an online course. I had studied online instruction intently in preparation for the course, but still managed to make some nice "rookie" online instructor 
mistakes. Although I thought the setup for the course was positive for the students overall, the workload it created for me (creating multiple videos a week, commenting on every assignment, etc.) probably would not have been sustainable for multiple semesters. During project 2, which was the focus for this study, I attempted to position myself as a mentor or facilitator during the research process, empowering students to make decisions, but also helping them work through challenges as they arose. I was also a participant in some of the student studies, particularly surveys that they sent out to the whole class.

In chapter 3 of this thesis study, I explore our class's answers to the first research question: How did literate activity occur in our online ENG 101 course? I present summaries of each student's work, put their work in conversation with other scholarship in the field, and discuss the affordances and limitations of their work. In the process of compiling that chapter, my positions as an instructor, researcher, and participant in the study were intertwined. My position(s) certainly afforded me more voice and a greater level of agency in this particular space; however, I would contend that those students (such as Wes and Joe) who opted to submit their work to the GWRJ took up formal/public researcher agencies of their own beyond the course.

In chapter 4, I describe the results of the focus group and coded analysis. Again, I invited my co-researchers to co-construct an understanding of what our research should focus on, but my position in the group still informed the process - perhaps for better and for worse. On the one hand, students might have been more comfortable expressing views that differed from mine had a disinterested researcher conducted the focus group; however, my teacher-student relationship with the co-researchers also meant that I was 
able to draw on my shared experiences with the students as we co-constructed our understanding of the course.

For me, one of the greatest challenges of implementing a co-research methodology was my inability to realize a more egalitarian relationship with my coresearchers. The intrinsic power structures make a completely decentralized research approach unattainable. However, one of my greatest goals throughout the project was to position myself as a learner. As an instructor, I believed that I had things I could teach the students, but as a learner, I believed the students had things they could teach me.

\section{Concluding Thoughts}

With its emphasis on encouraging participants to conceive of themselves as researchers, the co-research model served as both a guiding methodology and a pedagogical tool in this study. Chapter 3 presents findings from the investigation my coresearchers and I did together during the course, while Chapter 4 draws on my collaborations with Sam, Claire, Joe, and Mark beyond the course. In addition to answering the two central research questions in this study, both Chapters 3 and 4 provide something of a meta-analysis of the research process itself, which allows us to explore the efficacy of co-research as a methodology and pedagogical tool. 


\section{CHAPTER III \\ WHAT WE LEARNED ABOUT OUR CLASS TOGETHER: CO-RESEARCH AS METHODOLOGY}

This chapter provides results and discussion related to the first research question: How does literate activity occur in an online Composition as Critical Inquiry Course? To answer this question, each student in my ENG 101 course selected his or her own research question that fit under the umbrella of the larger question we were trying to answer together. They then designed and carried out research projects using a variety of empirical and textual methods. At the conclusion of their projects, each student (or pair of students in one case) wrote an article about their study for the Grassroots Writing Research Journal (GWRJ). These articles gave students the opportunity to share their research findings if they wanted to do so. Though students were not required to submit their work to the journal, some did choose to do so, and at the time of writing this, they are involved in the review process.

This study employed a co-research methodology (the instructor researching with the student researchers) for two primary reasons. First, working with student researchers invites a different set of eyes to weigh in on problems that concern both the field of English Studies and the students themselves. The student researchers operate from different subject positions than "traditional" researchers and thus might offer us new ideas from their unique perspectives. Secondly, the co-research model may afford 
students greater agency in the research process than they might have as mere participants. Co-research specifically invites participants to conceive of themselves as researchers, offering them the opportunities to define questions, select methods, present and take ownership of the work.

Throughout this chapter, we explore the extent to which we did and did not realize the goals of the co-research methodology. The first portion of the chapter presents summaries of six student studies, each followed by a brief discussion of the affordances and limitations of the study in answering our class's shared research question: How did literate activity occur in our online ENG 101 course? The last portion of the chapter includes a discussion of the affordances and limitations of the co-research methodologies that this study made apparent.

\section{Adela's ${ }^{7}$ Study: "How Were Our Discussions Different on Google Drive vs. ReggieNet?"8}

Adela's study explores how discussions on the two platforms we used in the class—Google Drive and ReggieNet—went differently. Citing one of our class definitions of genre, "a text that makes an activity possible or impossible," she characterizes Google Drive and ReggieNet as the "genres" that made our class possible. For one part of her study, she surveyed her classmates on their preferences between the two platforms. The survey asked participants to rank each platform on a scale of 1 (worst) to 5 (best) based on how well each participant felt the platform facilitated the following functions: communication, saving/submitting work, and "technical things (not crashing

\footnotetext{
${ }^{7}$ Students who opted to join the project as co-researchers are identified by name, while those who preferred to keep their identities anonymous were assigned pseudonyms.

${ }^{8}$ The quoted material in the section headers are the titles the students gave their articles.
} 
and shutting down)." The survey also asked participants two open-ended questions about the features they found most inconvenient about each platform and whether they had comments on any other aspect of each platform.

Based on her survey, Adela found that the class preferred Google Drive to ReggieNet but found that ReggieNet was better for certain functions like private communications between individuals. She briefly characterized the different features of each site as actors and suggested that many actors work together to make the internet.

In addition to the survey, Adela analyzed her own engagement in discussions on the two platforms. She noted that grading influenced her level of participation and described a different level of intimacy in the conversations on Google Drive vs. ReggieNet:

I think our small groups in Google Drive somewhat forced us to communicate more comfortably because we've been assigned to the same small groups for the whole semester, and ReggieNet is more of a free-forall ... and it wasn't restricted to 3 or 4 people in our small group activities.

Adela ultimately concludes that the class seemed to have a preference for Google Drive over ReggieNet even though she felt her participants failed to clearly articulate why they liked one over the other. She suggests that one possibility was that the other students, like her, had experienced automated time-outs on ReggieNet that caused them to lose work. In contrast, Google Drive auto-saved their work.

\section{Reflecting on Adela's Study}

Adela's study offers us access to her felt experience of interacting with the two platforms that facilitated much of our literate activity in the class. Having a preference for Google Drive over ReggieNet myself, I was intrigued by Adela's conclusion that the 
preference was more a matter of disposition than a weighing of the platforms' actual features. Adela's research also accessed accounts of experiences with the platforms that I was not aware of (e.g., time-outs causing lost work).

I am torn in deciding whether or not I agree with Adela's characterization of Google Drive and ReggieNet as genres. She explains how the platforms fit our class definition of genre in that they facilitate activities; however, I also emphasized throughout the course that a genre must be a text. We broadly defined text as "something we use to make meaning." Google Drive and ReggieNet housed our course texts and dialogs, but to what extent did they participate in helping us make meaning? Where is the distinction between text and context? Genre and activity system?

Along with its insights, Adela's study does involve certain limitations. We see evidence that she is a novice researcher in her choice of survey questions and in the limited depth of her analysis overall. Though she set out to analyze the differences in discussions between the two platforms, her ultimate product told us more about student preferences for the two platforms than how writing actually happened on those sites.

However, these student preferences do offer us an interesting insight about literate activity as it is facilitated by LMSs. Students' dispositions towards the LMS may be shaped by factors other than functionality. Further research might explore what design factors can make an online classroom environment not only functional but comfortable for learners. In developing a critical awareness of the LMSs, Adela enacts Van Ittersum \& Lawson Ching's (2013) recommendation that students do more than passively accept their online classroom environments. 


\section{Wes's Study: "Where Would This Article Be without Peer-Evaluation?"}

Since the course involved heavy levels of peer interaction and review, Wes opted to focus his research on how peer review facilitated better writing in the course. He begins his article by discussing how peer interaction helped him better understand $\mathrm{CHAT}^{9}$ and then went on to say that CHAT sub-concepts like socialization helped him better understand peer review. The multiple perspectives that go into peer review lead to a well-rounded product. Texts can also be described as social because writers derive inspiration from interactions with the social world.

Wes claims that peer evaluation as a genre facilitated multiple activities in the class. It both helped the writer improve and helped the peer reviewer deepen his or her own understanding of the concepts. Wes writes, "If someone can read a text, analyze what the person is trying to explain, and find what needs to be improved that is just as beneficial as reading a book and taking a test" (Wes, p. 3).

Wes supports his claims about peer review with secondary research. He also used his article as an experiment in peer review. The second half of his article shows excerpts from an earlier draft of his piece along with the peer comments he received. He breaks down each section and explains how the peer feedback led to specific revisions. Specific revisions included decisions to break up paragraphs, adding a more explicit discussion of CHAT, supplementing his ideas with specific examples from the class's activities, and explaining some of our class projects more clearly for audiences outside the class.

\footnotetext{
${ }^{9}$ An excerpt of the document we used to define CHAT and other terms in the class is included in Appendix B.
} 


\section{Reflecting on Wes's Study}

Since Wes plans to go into nursing, he focused his first semester project on researching and developing a treatment plan. After his first draft, I recommended he interview a nurse to get a better sense of how the genre functioned. Wes later reflected that interviewing someone who has direct experience with the genre in its activity system was some of the most valuable research he did. I feel similar about Wes's research on peer review. As a teacher researcher, I might have been able to examine the student documents and draw some conclusions about the effectiveness of peer review in the course, but Wes's study offers a deeper student perspective on how this literate activity occurred. As one who both performed and received peer review in the course, Wes's perspective will be inherently different than mine.

In a way, Wes's study was useful feedback for me as an instructor to know that the setup of the course was effective (at least for some learners). Many class genres encourage students to reiterate what their instructor has said in hopes that the instructor will view their work positively and give them a good grade. Wes's decision to focus on the successes of peer review in the course suggests that he really did internalize the benefit of collaboration in the writing process. He writes, "Writing is something that is never done alone even though it may seem like it. ... More than likely, something that you write is inspired by another prior text that you have seen or read" (Wes, p. 2).

Wes also reports on an important position shift that happened in our course because of our consistent peer review practices. He writes, "Many times in my blog posts, I mentioned my peers because they were a major part of how I learned!" (Wes, p. 5). At least from We's perspective, peer review allowed the students to take on a more 
authoritative teacher or researcher role. Wes credited his peers in his blogs in much the same way that a researcher might credit the other researchers who informed a particular idea.

Wes's entrenched researcher position is also somewhat of a disadvantage. While he describes getting a lot out of peer review, I do not feel that this was the experience of all students in the course. Much like a case study, Wes's research offers us a deep look at one incident but does not necessarily offer universal take-aways for implementing strong peer review in other contexts. Even as a single example, though, Wes offers an insightful counter-narrative to Rendahl \& Breuch's (2013) claims that students do not value peer interaction in OWCs.

\section{Katie's Study: “Underlying Identity: Online vs. Face to Face Classes"}

Since the $G W R J$ allows for some deliberate deviations from the traditional academic article form, Katie opted to present her research as a fictional story about Leroy, a shy lion who opts to enroll in an online class and examine how he represents his identity online vs. in a face to face (F2F) environment.

Leroy observes that he feels more comfortable in an online environment because he is able to remain relatively anonymous. He also showed higher levels of participation online than in a F2F environment. Later, he chooses to deepen his knowledge of these phenomena by interviewing some lions in a F2F class. The narrator suggests that the lions Leroy interviewed had more dominant personalities whereas Leroy was fairly shy. The lions in the F2F classes claimed that they enjoyed the F2F environment and felt that they were able to express their identities through clothing, conversations, and participation in class activities. 
Leroy then conducted a more thorough auto-ethnography of his activities in the online course. He examined his own coursework, his profile, peer comments, and other documents that allowed him to see how he was able to express his identity online. Leroy determined that the online course better allowed him to choose how he represented himself. He was able to display his personality through his profile, use of humor, and topic choices on projects.

Leroy then opted to branch out further and examine the profiles and introductory blogs of a few of his classmates. He noticed that some of the students described themselves thoroughly while others did not. Some included profile pictures, some did not, and still others included profile pictures with multiple people, making it difficult for other participants in the course to know which person in the picture was the student. Leroy also noticed variations in how different students used styles, fonts, headings, bullets, etc. to convey their personalities or sense of organization in their blogs:

Next, [Leroy] looked into their blogs. These especially showed who people were. Some people added a little more detail than others. You can tell that even by the way some people set things up that their personalities show a little bit. Some people like to write using cute fonts and organize using bold headings or bullet points. This would probably stand out as an organized and creative type of person. Also, you can tell who puts more time into their work than others. Some people write a lot and go into major detail while other people just write in a sentence or two to get their points across.

Even from subtle font choices, Leroy was able to determine a lot about the other students in the class.

\section{Reflecting on Katie's Study}

Katie's decision to take on a pseudo personality (Leroy) to represent her research echoes her conclusions about the comfortable anonymity in the course. Katie seems to 
conclude that online courses allow some students to better control their selfrepresentation. In an earlier draft of the article, Katie concluded that students' thoroughness in their profiles and their use of styles/typefaces allowed others to determine how seriously each student took the course. In my comments to her, I recommended that this might not really be the case. However, Katie's research emphasizes that, at the very least, teachers and students develop different perceptions of personality and identity based on a user's style/typeface choices. This is perhaps the online equivalent of the research that suggests that teachers assign grades based on neatness in handwritten documents. Katie points out that, much like DePew \& LettnerRust (2009) suggest, students embody their errors in distance learning interfaces. Without their actual physical selves present, participants in the course make judgments about one another based on subtle factors in their metonymous self-representations.

Katie's thoughts on how style/typeface choices informed her perception of others is perhaps what stood out to me the most in her study. While DePew \& Lettner-Rust (2009) emphasize how these sorts of decisions inform teacher perceptions of students, Katie demonstrates that students are also judged by other students. This is significant because, as Wes's study demonstrates, students in online classes do have some power and authority. We are often attentive to helping teachers become aware of their inadvertent perceptions of students, but to what extent do we strive to help students understand how they are perceiving one another?

As Katie felt comfortable in the online environment, her research does not always account for the experiences of students who did not feel comfortable in the class. While an online class may indeed afford some students greater control over their self- 
representation, not all students are equally skilled in this activity. As Sherblom, Withers, \& Leonard (2013) point out, students' diverse technological literacies prior to the course have a significant impact on their abilities to represent themselves in the OWC. When I met with the students one-on-one face-to-face midway through the semester, many of the personalities that showed up in my office were a mis-match from the people I thought I had met online. Clearly, not all the students were equally adept at representing themselves in our mediated class environment.

\section{Claire and Sam's Study: "Being an Introvert in an Online Class"}

Claire and Sam begin their article by explaining the early part of their collaboration. When they selected research questions, I saw that they had similar interests and recommended that they work together in some capacity. (I offered to let any of the students in the course work together, but Sam and Claire were the only ones who opted to go this route). Both psychology majors, Sam and Claire describe how they wondered if social anxiety, which they suggest is common among young adults, might make online classes more comfortable for some. They were especially interested in seeing if introverts were better able to express themselves online. As they were both introverts, they opted to interview one another.

They also used an autoethnographic approach, analyzing their own work from the class and comparing it to their experiences in F2F classes. They found that they tended to go into greater detail when introducing themselves online vs. in F2F environments. They claimed they experienced less anxiety about peer perceptions in part because they had more time to think about what they were going to say about themselves compared to onthe-spot icebreakers in F2F classes. They hypothesize that because students often come 
into online classes with social media experience, they may transfer in these experiences when trying to represent themselves online.

Sam and Claire conclude the article by exploring the differences of online and F2F courses through some of the lenses of CHAT:

- Ecology: Online classes allow students to choose their own most comfortable space. The classes also allow for non-voiced interactions with peers.

- Reception: Students in online classes are more comfortable giving negative feedback to peers. Doing this in person is more difficult.

- Representation: Students in online classes may find it easier to represent their personalities and opinions. Sam and Claire suggest that this is especially true when students have opinions that differ from those of the majority.

- Socialization: Sam and Claire suggest that doing peer review in online courses is easier because students do not have to get to know one another first.

\section{Reflecting on Sam and Claire's Study}

As in Katie's research, Sam and Claire touch on the theme of having greater control over self-representation in the online environment. They focus heavily on the affective factors that make the online environment ideal for some learners, but also mention time and space as important aspects of the online ecology, which Warnock (2009) agrees are positive characteristics of OWCs. One of the challenges of online writing research is understanding how the off-screen activities inform the on-screen activities (c.f., Gillam \& Wooden, 2013). Sam and Claire offer a brief glimpse at the embodied experiences of learners in this course. I was also intrigued by their mention of social media as an antecedent genre/activity that informs students' behavior in an online 
class. As this course was both "online" and a "class," I suspect that the teacher and learners alike probably transferred in their knowledge and expectations from antecedent online environments and F2F classes. Andrews \& Varenne (2011) suggest that this is the case, and Sam and Claire's study points out that some students are conscious of this transfer happening. To be honest, my transfer of practices from antecedent online spaces to the course was not something I was consciously aware of, so Sam and Claire's study made me think more about my own subconscious uptake.

As with Katie's research, Claire and Sam's article offers a somewhat narrow perspective. Neither Katie nor Sam and Claire interviewed students who described themselves as more extroverted to test whether the affordances of online courses were limited to introverts or students with particular personalities.

\section{Mark's Study: "Are We Aware?"}

Mark set out to explore how uptake is articulated. He defines uptake as "how we absorb experiences and understand them or how we go about processing information until it makes sense to us, if ever." (Mark, p. 1). He suggests that research can prepare us to take up new experiences but that some uptake happens subconsciously.

Referring to a class video on uptake, Mark suggests that practicing awareness leads to better awareness. He traces how my decision as an instructor to assign a YouTube video in an online class demonstrates uptake and an awareness of context.

Mark used autoethnography to analyze his own uptake. He reflected on his own thought process and reviewed his documents from the course. He says he took up the concept of uptake easily, in part because he has three children, and he observes them taking up new experiences all the time. He gives the example of showing his kids a 
typewriter for the first time and talks about how the kids immediately connected the typewriter to their antecedent knowledge of computers and printers.

Mark concludes that uptake is always going on, but uptake awareness is what really makes the difference.

\section{Reflecting on Mark's Study}

Mark's article underwent major revisions from draft to draft, and he wrote in his reflection documents that he felt that the research never quite came together as he had hoped. I agreed with his self-assessment; the final article had interesting ideas, but it was somewhat unfocused.

That said, though, I feel that Mark's insights in the article and throughout the semester informed my uptake of uptake. Mark frequently described the sensory experiences and emotions that contribute to uptake. His alternate perspectives helped me understand that learning is as much a physical and felt process as it is a mental and logical process. Gillam \& Wooden (2013) support this view of embodied knowledge production. I tend to think of myself as more of a "thinker" than a "feeler," but my interactions with Mark have helped me understand that these false dichotomies that we set up can inhibit us from capitalizing on both the conscious and subconscious uptake we are practicing. He writes, "Being aware leads to greater awareness and greater awareness leads to being more aware." As I would paraphrase this, the more we can become aware of our conscious and subconscious uptake processes, the more we can intentionally activate these processes in new situations. 


\section{Joe's Study: "How to Hit a Home Run in Uptake"}

Joe analyzed his uptake blogs from the course to determine how his use of baseball metaphors informed his uptake. The article itself uses baseball metaphors throughout to explain uptake. He explains how in week 4 of the class, he used a baseball metaphor to explain the "history" aspect of CHAT and that using the metaphor also helped him understand uptake. He goes on to say, "Every pitch a pitcher throws, they are transferring in knowledge from previous pitches, innings, and even games” (Joe, p. 4).

In addition to analyzing his own work, Joe interviewed a classmate (Wes) about how the baseball metaphors helped facilitate Wes's uptake. Wes brought up that although the metaphors were helpful to him, metaphors may not be the uptake method of choice for everyone. Others have different learning styles. Joe takes up this idea and discusses how uptake is both a matter of timing and individual preference. Effective uptake requires knowledge of both personal learning methods and the appropriate environments where those methods will be effective: "If you use your learning method at the wrong time, it won't necessarily be pretty to watch" (Joe, p. 5).

Joe talks about hitting an uptake "grand slam," where picking up one concept helps you pick up several concepts at once. In social situations, sharing your uptake may help others pick up new concepts as well. He suggests that after experiencing success, people need to look back at the steps that led them to that success so they can see if the techniques can be used elsewhere. Joe concludes the article by recommending that readers practice autoethnography to determine which learning strategies work best for them. 


\section{Reflecting on Joe's Study}

When I met with Joe to discuss his research interests, I brought up that others had mentioned his baseball metaphors in their blog entries as something that facilitated their uptake. So, I "pitched" him the idea of exploring how he used metaphors in the class, and I felt he knocked it out of the park. Joe's uptake of uptake helped facilitate my uptake of uptake. Joe's exploration of metaphors as an uptake strategy helped me realize that I was also using metaphors as both an uptake strategy and a teaching device. Both Joe and Wes used metaphors in their blogs to explore abstract ideas. Wes in particular used hypothetical stories to explain new concepts.

I was also intrigued by Joe's recommendation that individuals who are new to uptake use autoethnography to determine which uptake strategies work best for them. This seems very similar to Mark's notion that the more we become aware of our uptake the more we will be able to use it. I have actually already actively incorporated these ideas into my own research on uptake. In preparation for a workshop I co-led at the Conference on College Composition and Communication, I mentioned Joe's and Mark's

findings with my co-facilitators as we discussed ways to efficiently convey the concept of uptake to our workshop attendees.

\section{Synthesis of Our Findings}

Despite only having seven participants / co-researchers, the above materials are a fairly representative sampling of the investigations that the class as a whole undertook. Several of the researchers not represented here explored similar topics. So, how did literate activity happen in our online ENG 101 course? This section synthesizes what my co-researchers and I found out. 


\section{The Online Platforms Facilitated (Some of) Our Activities}

As Adela's study suggests, our two platforms - Google Drive and ReggieNet—

played a fairly major role in our interactions. The structure of each platform changed the ways we interacted with one another in each space much the same way that a different arrangement of seats in a F2F classroom might alter interactions in that space. Our learning platforms were important actors in our activities, making it possible for us to read the same materials, hold conversations, submit and grade assignments, and much more. At times, they also inhibited activities. Adela offered the example of ReggieNet timing out and losing her work. Other students experienced difficulty submitting assignments. I personally found that both systems sent me so many automated email notifications that I sometimes missed actual emails that students or others sent me.

Despite the attention we dedicated to our virtual environments, we had very little discussion about our diverse physical environments or bodies. We did not demonstrate a strong awareness of our physical, embodied experiences (though the emphasis on sensory learning in Mark's study might be one exception). Though we all "did class" in disparate locations, we did not discuss much about how those material ecologies played a part in our knowledge construction processes.

\section{We Got a Lot out of Interacting with Our Peers}

Though not directly in his study, Wes mentioned to me at one point in the semester that although my comments on students' work were helpful, the students were getting plenty of constructive feedback without my help. Wes's project represented one of several studies in the class that tried to tap into the question "Why were my interactions with these complete strangers so constructive?" We identified a number of 
factors that may have made this phenomenon happen. As Adela mentioned, our small groups on Google Drive encouraged comfortable communication. The consistent groups throughout the semester may have allowed the class to establish stronger connections with at least a few students in the class. Sam and Claire pointed out that having more time to formulate responses allowed for greater depth and control over what we said. Wes and Joe's interactions also demonstrate that students' alternate explanations of concepts sometimes helped facilitate uptake more than the instructor's explanations.

\section{We Had to Figure out How to Represent Ourselves Online}

Katie's and Sam and Claire's studies demonstrate that we were interested in how we go about "being ourselves" online. As both of these studies showed, the online environment actually made self-representation easier for some students than the F2F

classroom. Some students valued the control the online environment gave them over their self-representation. However, as Katie's analysis of typefaces and styles suggests, we may not have always been completely aware of how our choices impacted the way that others in the course "read" us. Students' varying e-literacy skills may have impacted their ability to represent themselves online. As Sam and Claire point out, for example, those who drew on antecedent knowledge of online social networking might have been more successful at representing themselves in the online space than others.

\section{We Both Struggled to Take up Uptake and Found it Fascinating}

Though not directly related to our online environment, uptake was a source of interest for us in the class. Many students expressed difficulty understanding and articulating uptake. For example, Joe, despite his articulate discussion of uptake in his final project, talks about how it was several weeks into the course before he felt he 
grasped what uptake was. On the other hand, Mark reports (and I agree) that he took up uptake quite quickly. As both Wes's and Joe's studies demonstrate, peer interactions played a big role in helping the class take up uptake (as well as other concepts). Wes, Joe, and Mark also all used stories and metaphors as an uptake strategy.

\section{Reflecting on Co-Research as Methodology}

The above findings offer some answers to the first research question in this study: How did literate activity occur in our online Composition as Critical Inquiry Course? However, this study and its results may also shed light on the efficacy of student coresearch as a methodology. All methodologies have strengths and weaknesses, so this final discussion delineates some of the affordances and limitations that we encountered using co-research in this study. Note that this section does not attempt to detail the pedagogical implications of this research, as that will be covered in Chapter Four.

\section{Affordances}

One of the primary affordances of co-research as a methodology was that we were able to examine a wider range of activities in the course. The research activity itself requires time as well as physical and mental resources. By distributing the work amongst multiple researchers, we are physically/mentally able to conduct more exhaustive research in a limited amount of time. Our diverse interests also led to wider investigations because the co-researchers pursued topics that may not have initially caught the attention of their peers or their instructor. On a very basic level, I think it important to note that I learned new things from my students. They had insights I would not have had or shed new light on concepts I thought I already understood. 
The subject position of the co-researchers as students was also helpful. First, as nascent researchers, they were not yet socialized into all the language, perspectives, and norms that dictate the activities and thought processes of professional researchers. In other words, not having an ingrained sense of what they are "supposed to do" actually allowed for more creative approaches. The co-researchers also saw the course from a different angle because their student role demanded that they perform different activities. As the instructor, some of my course activities included creating schedules, generating assignments, and evaluating students' work. The co-researchers' primary activities included completing assignments and commenting on peers' work. The activities that the students and I performed were quite different, so involving student perspectives on those activities allowed for a more holistic examination.

\section{Limitations}

Along with its affordances, the co-research methodology also involved limitations. While I believe it would be inaccurate to characterize the students as "new" researchers (as this would flagrantly dismiss any value in their past experiences), it may be appropriate to say that they are non-professional researchers. As such, the students understandably did not always achieve the level of analytical depth one would expect from a professional's research. Their work, therefore, may not quite satisfy all the same functions as traditional research article genres.

In large part, the students' articles differed from those of professional researchers because the activities they carried out in their research processes differed from those of professional researchers. In the students' surveys and interviews, for example, their questions were not always appropriately structured to elicit detailed responses. 
Frequently, they asked questions that did not even relate directly to their central research question. Likewise, in their actual articles, they tended to focus on their own perspectives of the course. While their subject positions allowed them to report some valuable ideas, they sometimes failed to account for the fact that their experience was not the same as everyone else's experience in the course-let alone the experiences of those outside the course.

Meyer \& Land (2005) discuss the process of becoming a professional in a particular social group (e.g., physicists, teachers, etc.) through the acquisition of threshold concepts. Belonging to a particular social group (researchers in this case) requires members to grasp key fundamental concepts that Meyer and Land describe as both transformative and irreversible, meaning that once people acquire them, they become slightly ontologically different people. They are incapable of seeing things the same way they did before they internalized the threshold concept. I would argue that while the students in my class were certainly in what Meyer \& Land (2005) call the "liminal" spaces where they are able to explore the threshold concepts, the students have not yet fully traversed the important thresholds that one crosses in becoming a professional researcher.

Many of the additional limitations of the methodology came from our positioning the research in the context of a course. Since completing the research project was part of the students' grade, they did not have a high degree of choice about whether or not to do the research (although the decision to have their work represented in this study was, of course, optional). The framing question for the project, How did literate activity occur in our online Composition as Critical Inquiry course, was set up to be quite broad, but it 
still drew fairly strict boundaries around what research questions the students were able to generate. Ultimately, the automatic power structure in the course with the teacher as the lead investigator meant that the students could never be fully "equal" researchers. As teachers, we can distribute agency as much as we want, but we are still the ones doing the distributing. These limitations do not necessarily invalidate findings from student coresearch. Even professional researchers are subject to parameters and limitations to their investigative freedom. These limitations simply mean that although co-research as a methodology theorizes a democratic process with truly distributed agency, actualizing this goal may be difficult if not impossible in the actual implementation.

Whether or not the co-research model truly allowed the students to identify themselves as researchers has pedagogical implications in addition to methodological ones. Chapter 4 explores whether and how the students took up writing researcher identities as they completed the study described in chapter 3 . 


\section{CHAPTER IV}

\section{BECOMING WRITING RESEARCHERS:}

\section{CO-RESEARCH AS PEDAGOGY}

This chapter provides results and discussion related to the second research question: What writing research skills, knowledges, and identities did the students take up and demonstrate as they participated in a co-research project? To answer this question, I held a focus group with four student co-researchers from the class about two months after the class ended. We were a month into the spring term, and three of the four students were enrolled in Introduction to Communications (COM 110), which is usually sequenced in the opposite semester as ENG 101 in the general education curriculum. In the focus group, I invited the students to generate a list of the skills and knowledges they felt were essential to being a writing researcher, and then we discussed the students' uptake of writing researcher identities.

Following the focus group, I coded selections of the students' work from ENG 101 using the terms we generated in the focus group as nodes. I coded each student's Uptake Blog ${ }^{10}$ (13-15 entries each), GWRJ Genre Analysis, and Research Reports. The blogs allow us to trace the students' thinking throughout the semester while the GWRJ Genre Analysis and Research Reports show us deeper analysis and thinking related to the co-research study itself.

\footnotetext{
${ }^{10}$ See Appendix A for a description of the Uptake Blog assignment. Appendix C includes the Genre Analysis Assignment, and Appendix D includes the Research Reports assignment.
} 
I selected these methods for this portion of the study for a few reasons. First, I wanted to continue to extend agency to the students as co-researchers in the process because I valued their insights. Although this portion of the study did not give the students the opportunity to define their own research questions or select methods for the investigation, it at least gave them a voice in defining what we should be looking for. Secondly, allowing the students to generate the nodes for the textual analysis allowed me to focus on the skills and knowledges that the students consciously took up. While I could have coded their work in-vivo or against the learning outcomes I set at the beginning of the semester, I wanted to consider those skills and knowledges that the students themselves deemed valuable enough to mention. Finally, using both a focus group and an analysis of students' work allowed me to ground the data to see if the students actually demonstrated the skills and knowledges they claimed they took up.

This chapter begins with an exploration of the skills and knowledges that the students took up and demonstrated during ENG 101. As I discussed in the methods chapter, the student co-researchers and I eventually determined that the distinction between "skill" and "knowledge" was not always clear. Thus, this section highlights the various skills, knowledges, strategies, and competencies that the students consciously took up and performed during and, in some cases, after the class. The primary categories of codes include awareness of genres and contexts, research methods, and selfknowledge. It is important to note, of course, that this list of skills and knowledges is neither exhaustive nor representative of every student's experience. Even within our focus group, one student may have taken up a particular skill while another did not. The evidence provided in this section supports the fact that these skills and knowledges were 
exercised in the course, but I do not mean to assert that every student took up every concept.

The last portion of the chapter focuses on students' perceived uptake of writing researcher identities. As is evident in the types of skills and knowledges that the students emphasized in the focus group, the identities they took up were primarily formal or academic. However, they did express an awareness of dormant writing research skills that they might be able to activate if the need arose.

One final note prior to diving into the results: I found the timing of the focus group very relevant when processing the results. Kill (2006) discusses the concept of uptake memory, which roughly defined, suggests that students' past and present experiences inform what they take up, how they take it up, and how they remember taking it up. As I mentioned before, three of the four students were a month into their COM 110 course. For the sake of better understanding uptake, I note throughout this chapter places where I thought the skills, knowledges, or values that the students mentioned may have been intertwined with or influenced by experiences in other situations besides ENG 101.

\section{Awareness of Genres and Contexts}

The first major knowledge / skillset relates to productive awareness of genres and the contexts where those genres participate. In the focus group, the students generated the codes GENRE, CHAT, and AUDIENCE AWARENESS, and I later added the code TECHNOLOGY AWARENESS (see chapter 2 for rationale behind the addition of this code). In Downs \& Wardle's (2007) discussion of a writing studies approach, they suggest that FYC should teach students about the content and research of our field (much 
like a general education biology class) rather than treating writing skills as a service to other fields. Thus, this first section, deals with students' uptake of those key concepts to writing studies.

\section{Genre awareness}

In the focus group, the students briefly discussed developing writing researcher identities when they started practicing genre research in the first class project. When coding their work for evidence of genre awareness throughout the semester, the students demonstrated the ability to identify genre conventions, analyze genres through research, and perform genres.

The Genre Analysis assignments regularly asked students to break down the elements or "conventions" that make up particular genres. Figure 2 shows just a portion of Joe's discussion of the conventions of the Grassroots journal. Beyond this list, Joe also explained which of the conventions fit into a "prototypical" Grassroots article vs. which conventions might push the boundaries of what qualified as an article. The blog quote from Claire in Figure 2 shows how genre awareness helped Claire develop a nuanced understanding of grammatical conventions from genre to genre. Rather than applying the same standard grammar in all contexts, Claire recognized the need to let genre conventions and audience preferences dictate her grammatical choices. 


\section{- Paper}

- Black printed text

- Articles typed up by multiple authors

- Usually includes some type of bold headings to show different points in articles

- Special titles and short previews about the article

- Has a short write up about the author of each article

- Includes all the resources used by the author

- May include some type of pictures or illustrations related to the topic

- Research that goes into the article is required

- Main topic about some aspect of writing

- Intended to help people understand the different aspect of writing

- Tone varies from article to article but tends to be less proper and should not be consist of an authoritative voice or tone

- End usually contains a picture of the author

- Has page headings to help keep you in the right article

- Page numbers (Joe, Genre Analysis)

"[T] he rules for English and grammar (such as using contractions) varies and changes from author to author and the type of genre that they are writing. In high school I was always taught to use formal language (no using I or you, and no contractions). I learned that you can use whatever form of language you want, it just depends on what you yourself want to use, and the audience that you are writing for" (Claire, Blog 15).

\section{Figure 2. Students identifying genre characteristics}

In the focus group, the students explicitly discussed the relationship between using genre analysis to identify genre conventions and their development as writing researchers. Sam and Joe both described their experiences looking up samples of their genres to better understand how they would go about producing texts in those genres (see Figure 3). At the end of the semester, Mark identified genre analysis as an essential skill for a writing researcher, saying, "A writing researcher is a writer willing to explore all the aspects of a genre and create a product that will work in the genre or at least take on the process of this" (Mark, Blog 15). 
"For my project 1 I made like a YouTube video, just like a tutorial and like I looked a whole bunch of other videos of people that uploaded stuff. And I think it's important to have a broad range of everything to kinda get a better idea" (Sam, Focus Group).

[In response to the question, "When did you become a writing researcher?"] "I knew I wanted to do an advice column or a medical treatment plan and I know about those things, but I don't know enough about them to sit down and do it. I had to go back and research how to set things up, like what's the normal format for things? I just started researching what I was going to be doing" (Joe, Focus Group).

Figure 3. Descriptions of genre research

Besides analyzing genres, students regularly performed genres and developed an awareness of how those genres participate in broader activities. For project 1, Claire created an online how-to guide on playing the major chords on the piano. Reflecting on her project, she succinctly describes the relationship between genre and activity saying, "It takes a lot of work to create a how-to article because you have to do a good job explaining the task that someone is seeking to do, and if they fail you didn't write a successful article" (Claire, Blog 8). Interestingly, although we explicitly analyzed and performed certain genres for class projects, some of the students also began to think critically about the day-to-day genres they were performing as part of their regular class experience even though I never explicitly asked them to reflect on these genres. Claire describes learning to email professors and Joe describes how his performance of uptake blogs changed as he realized he had mis-transferred certain conventions from his antecedent genres in his early genre performances (See Figure 4). As Joe's comment illustrates, students also demonstrated the ability to identify when their performances did not match all genre conventions. In a similar example, Mark reflected on how his Grassroots article was a failed performance because it did not match the genre conventions: "When I turned it in I was not confident. I put a lot of time writing it but 
when you are told to make a triangle and you make a square well. ... That was not this genre at all" (Mark, Genre Analysis).

"As weird as it sounds, I actually learned how to properly contact and communicate with my professor using email thanks to this class. In the past if I had any trouble with anything, I usually just asked my teacher the next day at school. Since we didn't meet as a class, the only way to contact Ms. Sheets was through email, which helped prepare me to know how to communicate with professors in the future" (Claire, Blog 15).

"I noticed that my writings [in the early blogs] were also a lot of fluff, things that were inserted to make them appear to be longer, when in reality, it was just inserted for length. I feel as though this occurred because my previous English instructors valued length as a portion of our grade, thus my brain was trained to try and make writings as long as possible" (Joe, Blog 15).

Figure 4. Student awareness of genre performance

\section{CHAT}

In the focus group, the students identified CHAT as a helpful knowledge for writing researchers:

Mark: Is CHAT knowledge? Because I definitely think that helps.

Me: What resonated with you?

Mark: All of it.

Claire: I'd never been taught that in previous English classes, so I feel like when I take them in the future that will help me to always go back to that to break it down.

In class, we usually broke $\mathrm{CHAT}^{11}$ down into seven sub-concepts, so I sub-coded the students' work for evidence of engagement with each of the following: activity, socialization, ecology, representation, reception, distribution, and production. Within activity, students demonstrated an awareness fairly early in the semester of how texts and genres serve as actors that influence human behaviors in particular contexts. Sam and

${ }^{11}$ An excerpt from the text we used to define CHAT and other key terms in class is included in Appendix B. 
Claire recognized the very tangible evidence of socialization as they co-authored their Grassroots article, and Joe aptly described that the publication of a Grassroots article is always a process that involves multiple human participants. Claire's reflection on ecology demonstrates meta-awareness as she describes how her present environment influenced her composition of her discussion of ecology. Sam and Claire's Grassroots article deals heavily with the subject of representation, but in their genre analysis, they also discuss how the genre always already represents various cultural perspectives. In discussions of reception, Mark and Joe describe how different audience needs dictate how texts are made. Finally, the students also demonstrated an awareness that genre/tool production is rarely a single-step process. In the focus group, Mark discussed how CHAT helped him understand the complex activities that went into the construction of even small everyday objects. Likewise, Joe describes how the production of a Grassroots article involves more than simply sitting down and writing. 


\begin{tabular}{|c|c|}
\hline & \\
\hline & $\begin{array}{l}\text { "I really hope my how-to is descriptive enough to at least help someone get the idea } \\
\text { of how to play chords on the piano. I guess the only way to truly find out is for } \\
\text { someone to test out (which I might actually have someone do)" (Claire, Blog 8). } \\
\text { "I made a point about how important the baseball rule book was. It was only after } \\
\text { someone mentioned how much the game would be different if it did not exist" (Joe, } \\
\text { Blog 3). }\end{array}$ \\
\hline & $\begin{array}{l}\text { [Describing her collaboration with Sam on the Grassroots article] } \\
\text { "We learned that working together actually benefitted the both of us, and we worked } \\
\text { very well together" (Claire, Blog 14). } \\
\text { "Typically there are a group of people who are all involved in the production of this } \\
\text { text. The author is the main person involved in the text production. The others } \\
\text { involved include the people involved in the research, an editor, the people at } \\
\text { Grassroots who approve the article, and even a teacher or professor who puts an } \\
\text { author in contact with the people at Grassroots" (Joe, Genre Analysis) }\end{array}$ \\
\hline & $\begin{array}{l}\text { "Ecology is a part of chat that we have all experienced. For ex } \\
\text { this weekend so I am currently doing this assigment [sic] in m } \\
\text { at school however, I would be doing it in my dorm room with } \\
\text { blasting. When we were in grade school the teacher usually m } \\
\text { there was a writing assignment, however in high school the te } \\
\text { you needed to, and now in college you have to make the decis } \\
\text { environment you want to be in while writing on your own. Th } \\
\text { enviroment [sic] could possibly affect the quailty [sic] of my } \\
\text { 4). }\end{array}$ \\
\hline & $\begin{array}{l}\text { "The cultural values that are reflected in the genre depends on the cultural values of } \\
\text { the author of the article. If the author had to interview another person to use as a } \\
\text { source, their culture values could also be used in the article. Since the Grassroots } \\
\text { Writing Journal publishers have a final say in what gets published, their cultural } \\
\text { values may also be shown. The values shown in each article varies depending on the } \\
\text { author of the article. My previous English classes seemed to value formal language, } \\
\text { and as stated before these articles each vary in what they value depending on the } \\
\text { author" (Claire, Genre Analysis) }\end{array}$ \\
\hline
\end{tabular}




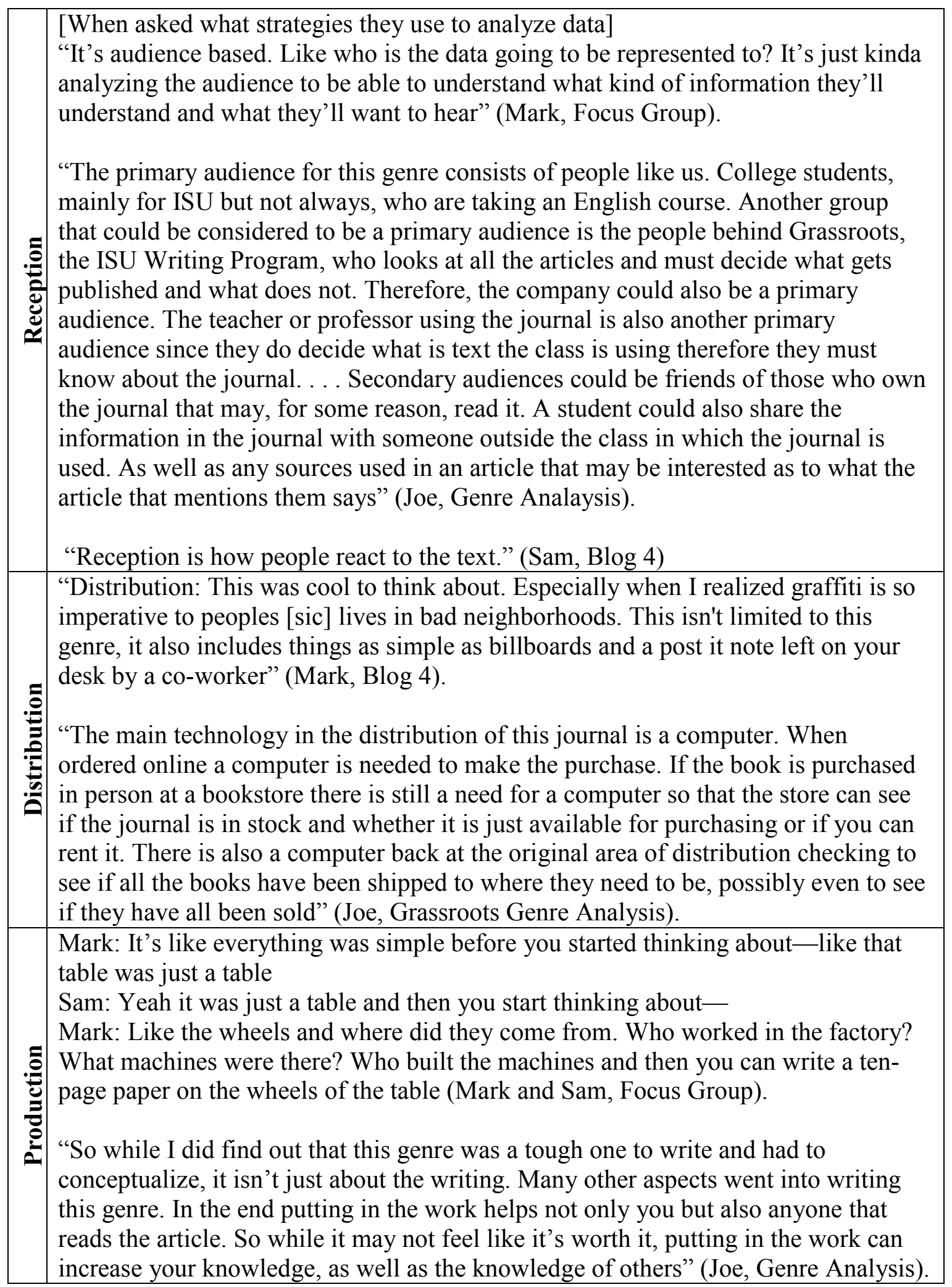

Figure 5. Examples of CHAT understanding and performance 


\section{Technology Awareness}

Since we were working in an online-mediated classroom, technology was a very tangible actor in the students' activities throughout the semester, and they demonstrated an awareness of the ways that their tools influenced their processes for better or for worse. Very early in the semester, Mark reflected on how his tools mediated his basic activities in the course (see figure 6).

"I lean forward and extend my arms out towards my laptops keyboard, the keys lit brightly from lights layed under them. My fingers hit the keys, they press in soflty with a crisp feel, and pop right back up. Letters come up on the screen and form words which eventually form sentences. Why did I mention the lights under the keyboard, the feel of the keys when I press them, the letters coming up on the screen which eventually form sentences? All of these things are actors in the process of writing this blog. The lights under my keyboard are a neutral actor as I sit in my brightly lit room. However if it was dark the lights would become non-neutral actors. They would help me see the keys and be able to remain accurate" (Mark, Blog 2).

Figure 6. Detailed description of technological mediation

As the semester progressed, the students were able to explicitly describe the tools and technologies they were using to facilitate their writing activities (see Figure 7).

"We both went back through and looked at our discussions, blogs, and comments from past weeks. We went back and chose work that we thought was an accurate representation of how we present ourselves in this class. As we were reviewing our past work we kept track of which pieces stood out to use the most in a word document" (Claire and Sam, Genre Analysis).

"I copied and pasted the results of the five respondents into a Microsoft Word document to make analyzing the data a more streamlined process" (Mark, Research Reports).

Figure 7. Descriptions of technology use during research process

Perhaps more interestingly, the students were able to diagnose problems that the technologies caused in their processes. Several students in the class attempted to use surveys to collect data for their project. I had had students do this in a previous F2F section of ENG 101, but my students this semester really struggled to find participants to 
take their surveys. Both Joe and Claire/Sam suggested that the nature of the online course environment made surveying their classmates more difficult (Figure 8). These reflections suggest that the students were able to think critically about the limitations of their tools and technologically mediated environments.

"We didn't have access to . . . other people in our class face to face (unless we met with them). At times it was frustrating when people didn't take our survey, something that could've easily been done if we had a face to face class" (Claire and Sam, Genre Analysis).

"I separated the questions that were asked on the survey from the ones asked during the interview by simply deciding which would require a more in-depth answer. Questions that I felt would be too tough to answer online, or questions that might raise confusion were asked during the [interview]" (Joe, Genre Analysis).

Figure 8. Awareness of limitations of technologically mediated environments

\section{Audience Awareness}

The students particularly stressed the importance of audience awareness in the focus group. When Mark emailed me after the focus group, he suggested that the very definition of writer researcher considered audiences: "I thought of one more definition of being a research writer: Being able to take a concept or idea and apply efficient and effective methods of research . . . to combine the data and produce an appropriate and well written product for the intended audience" (Mark, Email following the focus group, emphasis added). In particular, the students seemed to recognize that genres had multiple intended and unintended audiences whose needs differ. For example, both Joe and Mark offered detailed descriptions of a wide variety of audiences that might interact with the Grassroots Writing Research Journal (Figure 9). 
"The primary audience for this genre consists of people like us. College students, mainly for ISU but not always, who are taking an English course. Another group that could be considered to be a primary audience is the people behind Grassroots, the ISU Writing Program, who looks at all the articles and must decide what gets published and what does not. Therefore, the company could also be a primary audience. The teacher or professor using the journal is also another primary audience since they do decide what is text the class is using therefore they must know about the journal. Secondary audiences however, I am not too sure about. Secondary audiences could be friends of those who own the journal that may, for some reason, read it. A student could also share the information in the journal with someone outside the class in which the journal is used. As well as any sources used in an article that may be interested as to what the article that mentions them says" (Joe, Genre Analysis).

- Professors office or home for grading, using as an example of good or bad, help getting article published

- College students dorm room for assigned readings and ideas

- Published writers families homes to show off and be proud

- Present and previous published writers homes reflect on success

- Published writers friends homes show off friends abilities

- Editors and publishers at GWRJ help article get published

- I will use this as an antecedent experience to draw from for other assignments

- Campus bookstore

- College Library

- Online journal database (Mark, Genre Analysis)

Figure 9. Descriptions of the possible audiences for GWRJ

Although we did discuss audiences in the course, I was somewhat surprised by how strongly the students emphasized this concept in the focus group. Since three of the four participants were currently enrolled in Intro to Communications (COM 110), I wondered if the students might have developed somewhat false uptake memories. That is, they might have thought they "remembered" learning about robust audience analysis in ENG 101, when in fact, they had recently learned more about it in COM 110.

Kill (2006) offers an example of uptake memory that somewhat parallels what I observed in the students in the focus group:

Kirk Branch provides an example of uptake's memory when he describes a situation in which a student in an adult literacy program writes:

"Furthermore Mr. Kirk gives us our assignments and he has always 
wanted us to do our best. He said, 'If you hadn't improved your English, you wouldn't have got a good job"' (221). What is notable here is that Branch never said anything of the sort. This student's detachment of his representation of Branch from Branch's actual conduct, is, at least in part, a result of the fact that the student is not responding to Branch alone (the immediate utterance), but to Branch as one in a long line of teachers, and thus also to the theories he has developed about what type of situation this is and what subject positions are relevant. (Kill, 2006, p. 220)

Similarly, I would suggest that the students in the focus group were combining their understanding of the key concept (in this case audience analysis) but not necessarily differentiating between where/when they took up different aspects of the concept. They may have retrospectively considered audience analysis an important aspect of ENG 101 because their new (or possibly old) values emphasized this concept.

\section{Research Methods}

Another central theme of the codes the students identified in the focus group was research methods. The students felt that our research project exposed them to research strategies they had not previously used extensively, including library DATABASES, SURVEYS, INTERVIEWS, and OBSERVATIONS. They also commented on the value of practicing DATA ANALYSIS.

\section{Database and Search Engine Use}

The students put considerable emphasis on using databases in the focus group, mentioning them at least six times. Mark described taking up using appropriate search terms to find more relevant results. Joe suggested that learning to use the Milner Library database would help him use other types of databases in the future, suggesting that the skills he had gained would transfer to a variety of contexts. In their blogs, at least three of the students specifically mentioned expecting to find database knowledge / skill useful in their future academic careers (See Figure 10). 
"As for the future I feel like learning how to use the available databases will be a big help to me mainly in class, not just this class" (Joe, Blog 6).

"Overall, I'm very happy I learned how to use APA format and search articles on a database, as I'm more than sure that both of these things will come in handy for future classes" (Claire, Blog 6).

"I am also grateful that you introduced us to Milnar [sic] and showed us all the ins and outs of the database tool. I am positive that will help me in my future studies" (Mark, Blog 6).

"The Milner library is going to be a very big part of my college experience and [that] I am sure will help me with research" (Mark, Blog 9).

Figure 10. Student expectations about the usefulness of databases

I was surprised by the emphasis on databases in the focus group. Most of the students did not use secondary research as a primary strategy for their Grassroots article project. The only week we discussed databases extensively in class was week 6 (as is reflected in the blog quotes above), and we did not cover some of the techniques the students mentioned in the focus group (such as Mark's reference to using appropriate search terms). Again, since three of the students were enrolled in COM 110 at the time of the focus group, I wonder if that course influenced the students' uptake memory because COM 110 generally puts a fair amount of emphasis on using journal articles. However, the students did mention feeling like they had more competence with using the databases than did some of their COM 110 classmates.

Sam did not share the other students' enthusiasm about databases, reflecting on how she found scholarly journals and databases difficult to use in high school:

I think it's very hard to find what you're looking for which is really inconvenient. I always hated doing that in high school as well, so I'm sure my negative experiences before didn't help me at all. Once something has a negative connotation to me, it makes me less likely to want to participate in that particular activity. (Sam, Blog 6) 
Sam's comments shed light on another possible reason that the students emphasized database use so much. Their antecedent experiences may have stressed these skills, so the students might have valued database skills even if they did not feel they were particularly adept at them prior to the course.

Prior, et al. (2007) emphasize, "Mediated activity means that action and cognition are distributed over time and space and among people, artifacts, and environments and thus also laminated, as multiple frames or fields co-exist in any situated act" (p. 18). In the students' discussion of database use, we see both Kill's (2006) concept of uptake memory and Prior, et al.'s (2007) idea of lamination at work. The students' uptake of database use is and has been distributed over multiple environments, meaning that their understanding of databases in those environments informed their perception of the concept in ENG 101 both during the class and after the fact.

\section{Surveys and Interviews}

Unlike with databases, most of the students did not have much prior experience with conducting surveys and interviews before coming into the course. Joe, for example, reflected in Blog 12 that though he was able to transfer in his prior knowledge of taking surveys, he had never conducted his own. As they interacted with surveys and interviews as genres, the students became more adept at identifying the affordances and limitations of each tool in the context of the greater activity systems where the tools were used. Claire and Sam, for example, described reserving more in-depth questions for their interview while setting up multiple-choice questions for their surveys. Joe used primarily multiple choice questions and only one free-response question, hoping the format would 
attract more survey-takers from the class. Mark kept his survey quite simple, using two free-response questions.

On the whole, students reported that their interviews were successful. All of the researchers met $\mathrm{F} 2 \mathrm{~F}$ with their participants, and they reported achieving a satisfactory level of depth in the research. Joe, for example, was initially concerned that only one other student agreed to be interviewed, but he reports:

I was taken by surprise when my interview exceeded my expectations. The amount of useful information I got from my interview was enough to help my research take leaps in progression. After reviewing my interview I decided that I had recorded enough useful information to not need another interview and then proceed to my next research method. (Joe, Genre Analysis)

Besides the formal interviews conducted during the project, Mark and Sam both mentioned using interviews informally to gather information. In Mark's Week 3 Blog, for example, he describes how his curiosity about the genre of the license plate led him to interview a police officer friend. Sam likewise reported in the focus group that she interviewed her roommate informally as she was trying to decide on an appropriate topic for her upcoming informative speech in COM 110.

In contrast, most of the students who used surveys found the results unhelpful due to low participation. Significantly, though, those students who had unsuccessful survey results recognized that their data was not useful, describing in their genre analysis how they decided not to include the survey results in their final articles (See Figure 11). 
"We ended up having success in our interview and self observation research, but only two people took our survey so we ended up not using that information in our final article" (Sam and Claire, Genre Analysis).

"As for the survey, I did encounter some problems. Since it was just a survey online some of the questions were misinterpreted. Due to its online nature, I was unable to clarify the questions rendering them rather useless. I worked through this problem by simply throwing the question out from my research" (Joe, Genre Analysis).

Figure 11. Discussions of decisions not to use survey data

Perhaps as a reflection of his success with the interview and failure with the survey, Joe claimed during the Focus Group that these activities require greater planning and people skills in addition to knowledge of the genre:

I feel like you kind of have to have recruiting skills. You have to know how to make people interested in your work. You can't just go up to random people and be like, "Hey do you want to be interviewed for something?" because if they don't have any interest in it, they might not give you a thorough interview or something. Or if you're wanting to survey someone they might not take you seriously. (Joe, Focus Group)

Joe's comment suggests that the students may have taken up an awareness of the sets of activities involved in using certain research methods.

\section{Data Analysis}

In the focus group, the students discussed how they had taken up a new understanding of qualitative data analysis during ENG 101. As Joe describes it:

I feel like analyzing information really helped me because like coming into this class I wasn't really, I was mainly quantitative research and stuff and science and stuff. So I knew how to analyze numbers . . . but after coming out of this class in general, I was much better at analyzing all types of information. (Joe, Focus Group)

The students used a wide variety of data analysis strategies, adapting their approaches based on the type of data they were using (self-observations, interview transcripts, class materials, etc.), the question driving their research, and their own research preferences. 
Notably, they were able to clearly describe their research methods to offer support for the approaches they used. The examples in Figure 12 show students using comparative analysis, looking for trends and anomalies, using pre-set codes, and deriving codes invivo from the data. Some of the students used several different analysis approaches on their single project, suggesting that they had developed enough skill with data analysis to adapt to the demands of the situation.

"To analyze our data we reviewed each other's responses in depth and thought about the similarities and differences of our answers. We compared how we responded to each question and tried to relate it to the fact that we are introverted in face to face classes but extroverted in other situations (such as being with friends or this online class)" (Sam and Claire, Research Reports).

"The coding I used coming into this week was based on what I felt was important and I looked for points, both against metaphors and for them. I felt as though in order to write an adequate article and get the most out of this, I have to look through both the eyes of someone that uses metaphots and of someone who doesn't. For the codes on the pro-metaphor side I looked for things like people saying that the metaphor I used helped them, they can use metaphors in general, and if they feel as though metaphors are helpful. For people who don't necessarily use or understand metaphors I coded for things such as, why they don't like metaphors, why they might not use them, and again whether or not they feel like they are useful" (Joe, Blog 13)

"Finally, my other form of content research was self-research or an autoethnography. During this I simply went back and researched all the works I had done previously in the class. I compared them to each other, noticed differences, and tried to critique my own writing even more than what had been done" (Joe, Genre Analysis)

"When analyzing the free response questions, I went back through and typed out all the answers on a word document. This made it easier to compare each statement to each other. While comparing each statement I looked for common trends in answers. I also looked for commonalities in how each person perceived the metaphors. Analyzing it this way, I feel, gave me a better insight as to how the responders' reacted to the metaphors" (Joe, Research Reports).

"I knew I would be using my personal thoughts and experiences. This type of research is very exciting to me so I began reflecting and brainstorming right away. I took notes of new thoughts and experiences I had while conducting research. I read notes of thoughts and ideas I had throughout the semester. I read through some of my older coursework as well. I then transferred the more focused data into new notes to pick 
through, compare, break down and work off of' (Mark, Research Reports).

"Some of the keywords and phrases that influence my uptake were: smell, texture, thoughts, feelings, antecedent, body language, voice, cleanliness, level of difficulty, interest in material, and boring. My notes, blogs, and course work show that in my case emotions are more important in the process of uptake than logic" (Mark, Research Reports).

"I used keywords, which emerged from the data to analyze and seek out trends. I sought out similarities in the data to see if as a class we were on the same page, chapter, book, or library for that matter. I will talk about and explain the one anomaly I found in the data. ... Some keywords that I saw being used frequently in the responses were: learning, how, think, experience, understanding, process, apply, concept, and daily" (Mark, Research Reports).

Figure 12. Descriptions of data analysis approaches

It is conceivable that the co-research methodology for this project lent itself to helping students develop these fairly robust descriptions of their data analysis methods. The students observed data analysis in action a lot. I modeled several examples of my various approaches to data analysis, but perhaps more importantly, the students also reviewed their peers' Research Reports, which, in effect, led to some peer teaching and mentoring.

\section{Observations and Autoethnography}

All of the students in the Focus Group opted to use self-observation as a research method. For the most part, the students balanced their observation between reflecting on their own thought processes and critically examining the documents they produced in the course. Mark, for example, kept notes on his thought processes, but he also conducted critical analyses of his uptake blogs (see Figure 12 above). Similarly, Sam and Claire did a combination of self and other observation when they interviewed one another on their self-representation in the course and then examined their "Getting to Know You" documents from the first few weeks of the course. 
In our conversations about potential research strategies midway through the semester, many of the students were surprised that self-observation could count as a valid research strategy. Perhaps out of this reaction, Joe developed a fairly robust defense of his methodological decision to use self-observation as well as a detailed description of his methods for carrying out that self-observation (see Figure 13).

\section{Defense of Methodology}

"For my next research method, I decided why look any farther than myself? No one is able to understand my baseball metaphors [better] than myself. Thus I will reflect on my own writing and explore how my own writing has changed. My biggest point of research for this method will be, "how did my uptake change as I started to relate things to baseball?" I would like to research myself to see if my metaphors have really had as big of an impact on my writing as I feel they have. To complete this I will look specifically at things I have wrote down, my blogs, and forums. I will also try to see if they have, in a way, changed how I go about my writing process. Meaning I will see if my mind just automatically tries to relate things to baseball, or if my writing processes have remained the same. This will hopefully give me an insight to how my own writing has changed because of my own metaphors" (Joe, Research Reports).

\section{Methods}

"Finally, my other form of content research was self-research or an autoethnography. During this I simply went back and researched all the works I had done previously in the class. I compared them to each other, noticed differences, and tried to critique my own writing even more than what had been done" (Joe, Genre Analyis).

Figure 13. Joe's defense of methodology and description of methods

\section{Self-Knowledge}

Because all of the students (at least, in the focus group) used some form of autoethnography to research their Grassroots article, I asked them to reflect on the relationship they saw between self-knowledge and uptake. Joe responded:

I feel like you can't really write about how you learn something if you don't really know, if you don't look inside and see how you learn it. If someone asked you how did you learn basic math skills, you can't just say well, the teacher taught it to me. Well, teachers teach everyone else in your class and some people grasp it and some people don't. How did you look at it when they were teaching it? 
Our discussion of self-knowledge touched on both internal thought processes and external activities as students discussed the value of identifying what one does not know, activating antecedent genre knowledge, using process genres, and cultivating effective personal work habits.

\section{Identifying What One Does Not Know}

During the focus group, Mark asked me what I considered the most important writing research skill. After thinking about it for a while, I decided that identifying what one does not know was a central skill to me, and the students agreed:

Sam: I think that applies for any subject too because you think about math and when you tell your teacher oh I don't know how to do this, and they're like well what don't you know, what don't you get about it? And if you can't pinpoint what it is you don't know how to do then how are you supposed to move on from that?

Joe: You have to like know yourself

Me: Can we even say self-knowledge of how you learn or is that inaccurate?

Joe: it's really just self knowledge in general. You have to know not just how you learn but things you understand. Like she [Sam] was talking about how she made a YouTube video about guitar and if I tried to do that, I wouldn't be able to do it because I don't know how to play the guitar. You have to know what you know.

I asked students throughout the class to use their blogs as a space to express uncertainty and to clarify what they did and did not know. They seemed to struggle with this early in the semester, perhaps because school culture tends to stigmatize "not knowing" rather than viewing it as a productive place of potential inquiry. Particularly early on in the semester, students' discussions of what they did not know tended to be tidy narratives of problems that were miraculously solved through some unmentioned deus ex machina. Consider this example from Sam's week 4 blog: "Learning about 
CHAT this week was a little bit challenging for me at first, but now I have a much better understanding of it. I think it's very important to keep all these terms in mind for understanding genres better in the future" (emphasis added). Sam emphasizes that she "figured it out," putting more stress on the knowing than the not knowing. She completely omits the process that helped her take up the knowledge.

As the semester progressed, students became more adept at describing how they solved their "not knowing" problems (Figure 14). Their strategies included re-watching videos or considering examples, transferring in antecedent knowledge (and recognizing the limitations of that knowledge), consulting specific resources, and getting peer feedback from the class.

\begin{abstract}
"I was a little confused at first for all the things we had to do for the "mini-research" reports, but after looking at the example Ms. Sheets posted I quickly understood" (Claire, Blog 11).

"Coming into this week I knew about research, and how to research. However, I did not know much about how to write research reports. So coming into this week I transferred in my knowledge of knowing how to do research and conduct interviews/surveys to help me base what my research will be for project two. Coming out of this week I have gained knowledge about how to write research reports and what Mrs. Sheets will be looking for in a portion of the research reports" (Joe, Blog 11).

"The concepts this week were harder than they have been all semester. The citation styles can be a bit confusing to me. It isn't a huge problem because we have the resources to find the solutions. The grammar rules were also harder for me to grasp. I don't think I ever tried or even paid attention in high school so it makes a lot of sense as to why I find it confusing. I am going to keep pushing myself. I know I will eventually master or at very least learn it and apply it to my writings" (Mark, Blog 6).

"I thought some things about this week were easy while other parts were challenging. I thought my genre was a bit difficult to create a genre analysis for, but it definitely did get easier as I went along and it is very nice we get feedback from our classmates. It definitely helps a lot" (Sam, Blog 7).
\end{abstract}

Figure 14. Students identifying what they do not know 
At times, the students identified what they did not know, determined what would help them to learn what they did not know, but intentionally chose not to act on that knowledge. An example from Sam and Claire's Research Reports illustrates this:

We are not sure how much more we can go into detail about our results, since we both had similar answers to the interview questions. We think that it would be more beneficial to interview a larger group of people other than ourselves. If we wanted more accurate and varied results, we would do that.

Sam and Claire identified some areas of weakness in their research. Although they knew of an approach that could strengthen their data, they had to balance that knowledge with their awareness of the greater activity system. Would more interviews have made their study better? Perhaps. Was the time, energy, and resources necessary to collect that additional data worth it? Perhaps not. Like all researchers, Sam and Claire had to limit their research due to real-world constraints like deadlines.

\section{Activating Antecedent Genre Knowledge}

The students demonstrated varying levels of antecedent genre knowledge and awareness throughout the course. At times, these experiences allowed for low-road $\operatorname{transfer}^{12}$ (see Sam's comments in Figure 15), whereas at other times, they helped the students achieve medium- to high-road transfer (see Claire's comment in Figure 15).

\footnotetext{
${ }^{12}$ Perkins \& Salomon (1988) define low-road transfer as transfer between similar activities. High-road transfer is transfer between dissimilar activities.
} 
"Creating my youtube how-to video was very easy. I have had to create other videos for school in the past so I was familiar with how to do everything. Creating the video and uploading it was a simple and quick task" (Sam, Blog 8)

"The genre analysis for this week was easier than the previous one. I think the more exposure to these topics, the easier it gets" (Sam, Blog 10).

"In my Expository writing class my senior year I had to write a ten page research paper, and I felt like my skills from that class helped me write this article" (Claire, Genre Analysis).

Figure 15. Transferring antecedent genre knowledge

In the focus group, the students seemed to describe antecedent genre knowledge and life experience interchangeably, suggesting that they were drawing on knowledge of the greater activities and affects surrounding genre production not simply the genre form. For some genres, the students viewed life experience as a type of content research. Claire writes, for example, "People have to have prior knowledge of the topic they are giving people instructions for, or they have to do research on it so they give people accurate directions" (Claire, Blog 7). Both Joe's blog 12 comment and Mark’s Blog 7 comment (Figure 16) demonstrate transferring affective knowledge from prior experience. Joe's Blog 9 comment shows transfer of research strategies that do not necessarily relate to a specific genre. 
"I didn't always 'know' what decisions to make that would be the best for the outcome of my research, thus I did what I have always been told to do. Follow your gut feelings" (Joe, Blog 12).

"Past experience helped this week as well. I have had a lot of friends pass away as well as my father. I don't think it makes easier, it just makes it more familiar to think about. I realize the effect these individuals have had on me. That allowed me to list the effects and see which ones match up with this particular assignment. I have written letters to people before and it really is easier for me to release and share emotions in writing than in conversation. Even writing a letter and not giving it to the intended person is helpful" (Mark, Blog 7).

"In the past I have used a few different methods for research. The method that I have used the most in the past has been observations. It seems like for almost all of my research projects, I have done some type observations. The other type of research that I have done has been surveys. It is a method that I feel is relatively easier to complete as long as people are available to help. It might even be one of my favorite types of research" (Joe, Blog 9).

Figure 16. Transferring affective knowledge and research strategies

Prior knowledge and antecedent genre transfer was not always helpful to the students because at times the antecedent genres disrupted their understanding of new genres. However, when students were able to articulate their awareness of inappropriate transfer, they were generally able to address the problem. Joe's discussion of antecedent genres that influenced his Grassroots article offers a richly detailed description of both positive and negative transfer:

Antecedent genres had a large impact on the process I took to produce my product. The biggest help was the antecedent genre of writing up lab reports. I was able to transfer in my knowledge of how to write about my research results, which really helped me write about the results I got from my research. I was able to use some of the same concepts I used to write lab reports while writing my article. However, this antecedent genre also caused a slight mis-transfer of knowledge. I relied too much on my knowledge of drawing conclusions from my scientific data that I started to do that same thing while writing this article. I had to start my research reports over again due to this. So while this antecedent helped me, it also hurt me too. I also attempted to transfer some of my knowledge about research into this process, this did not help me because I had never completed the research that I had to do for this project. Therefore any 
knowledge I tried to transfer in was rather misleading. (Joe, Genre Analysis)

Not all of the students in the class achieved this level of antecedent genre awareness, but most were able to articulate connections between past work and present endeavors.

\section{Process Genres}

During the focus group, the students frequently referred to various types of process genres. I roughly define process genres as texts that facilitate the production of another text but are not necessarily visible in that final text. Common examples the students mentioned included notes, lists, outlines, and brainstorming. I was surprised by the students' emphasis on these process genres because I never explicitly taught any particular process genres. I did recommend that they consider using "planning” genres, and I even showed them examples of concept maps, bulleted lists, outlines, and other texts that I had recently produced as part of my own writing processes. However, I did not require students to use process genres at all, let alone a particular type. Thus, the students' use of and discussion of process genres demonstrates self-knowledge of personal writing practices as well the use of antecedent genres. It is conceivable that the students developed this knowledge of their processes as writers through their practices as writing researchers. As writing researchers, students traced their own uptake, which may have helped them identify the affordances of specific planning process strategies.

Although most of the students made use of a variety of process genres, I noticed preferences from student to student. Sam and Claire both seemed to like brainstorming and outlining. Claire mentions developing brief outlines even for minor assignments, and she also mentioned using outlining in her COM 110 course. Sam seemed to like 
brainstorming as a collaborative activity, mentioning multiple times that she found sharing ideas with others productive (See examples in Figure 17).

"From previous classes I transferred the the skill of brainstorming and outlining before I began writing any text that we were assigned. Even before I began a blog, I usually sat down for five minutes and wrote down a short bulleted list of the things that I was going to mention in that text" (Claire, Blog 15).

"My Comm teacher made us make a concept map.... So that's kinda like outlining or brainstorming" (Claire, Focus Group).

"Overall, I think working with a partner was very beneficial. It was much easier having someone to brainstorm with and someone to share thoughts and ideas with" (Sam, Blog 14).

"My comm class too because I'm in it this semester, and my roommate had it last semester and she's kinda familiar with my topic so I kinda interviewed her sorta like asking her about the topic and asking her about her experiences with her informative speech and just asking questions like that, so I guess that is kind of an informal interview" (Sam, Focus Group).

"I can use brainstorming such as making bulleted lists and other types of planning on paper" (Sam and Claire, Genre Analysis).

"The most important person in producing this text is obviously the author. They must first brain storm many thoughts and ideas on what they are going to write their article about" (Sam and Claire, Genre Analysis).

Figure 17. Use of brainstorming and outlining

Mark's preferred process genre was notes. He mentioned using notes both for class and for non-class related activities, and the notes seemed to satisfy a number of functions. In the focus group, he said that notes could help a person cultivate creative skills, and he suggested that he regularly keeps notes even if he does not always have a specific purpose for them. During ENG 101, Mark's blogs indicate that he used notes as a means of analyzing data and organizing his thought processes when he felt overwhelmed (See Figure 18 for examples). 
"Creativness is definitely a skill. And it's developed as well. You can't justsomeone's not born creative. It's something you can develop just by note taking and being able to change your ideas based on information that you find" (Mark, Focus Group).

"If I find something really interesting I'll take a note of it. Write it down. Even if it's just like something someone said or a quote that I like so I can use it in the future. So I think that being prepared is part of it" (Mark, Focus Group).

I read through the notes I took during my research and was able to compare trends using this manner. I looked at my old blogs to compare how I articulated my uptake for different weeks. I took all of this information and transferred it into a new set of streamlined notes containing data specific to my research (Mark, Research Reports)

"Uptake ended up overwhelming me in the end. There is just so much going on! Notes help and I am definitely working on it" (Mark, Blog 15).

Figure 18. Mark's use of notes

While Joe used a variety of process genres throughout the course, his discussion of genres that facilitated his interviews was particularly interesting. He talked about emailing participants to set up the interviews, writing interview questions in advance, recording and transcribing the interview, and analyzing data from the interviews. At the focus group, he suggested that each of these steps were necessary parts of the process of collecting and using interview data. 
"To ask people to from the class to participate I will send them an email via ISU email" (Joe, Research Reports).

I had to develop the questions for my survey, I also had to develop the content for my interview (Joe, Genre Analysis).

"Once in the interview, I recorded the interview on my computer, to make it available later as I begin to write" (Joe, Research Reports).

"To analyze my data, I replayed my interview and wrote down what I felt were important aspects mentioned in the interview. This consisted of writing down all the questions I asked during my interview as well as the answers that were received from the interviewee" (Joe, Research Reports).

"[A]s I replayed my interview and went over the data again codes that I had originally overlooked arose from my data, while other codes seemed to grow less important. . . . I was able to break things up into basic uptake thoughts, how metaphors affected uptake, and other useful things talked about in my interview. This process was aided by the use of highlighting each category in different colors. After that I was able to separate each category easier. Once the categories were formed, I was able to compare and contrast each individual category within its category. ... This helped me by filtering out, and finding out, what the major take outs from things talked about in my interview" (Joe, Research Reports)

Figure 19. Joe's use of process genres in interviews

\section{Work Habits}

A common theme that arose during the focus group related to the activities and habits not directly connected to writing that still impacted writing. A section of Mark's final blog speaks to a few of these sorts of activities:

Specific thing to transfer, Okay this is very simple. Do not think too much, or take on too much. Relax and go back to simpler assignments. Breathe. Use what you have learned and draw from this. Look at past notes. Email the professor for direction they will and do help. Milner is your friend. (Mark, Blog 15)

This blog entry emphasizes that writing is a broader activity that involves personal work habits in addition to direct knowledge of writing or research strategies. Two of the primary work habits that the students emphasized were finding an appropriate workspace 
and managing their time. I would suggest that the online environment might have influenced the students' uptake of these two themes. Since we did not meet in person, the students were completely responsible for selecting and controlling their own work environments. The lack of F2F structure also proved to be a difficult transition for many of the students, which may have prompted them to cultivate more effective time management techniques.

As students engaged with the concept of ecology in our study of CHAT, they began to examine their own working environments. Mark frequently mentioned where he did his work on a particular assignment (see Figure 20). In one of her blogs, Claire reflects on the concept of ecology while analyzing her ecology as she writes the blog. She emphasizes that now that she is in college, she has to make appropriate choices about her study environments in order to work productively.

"I went to Milner when it was time to transfer my findings into actual data. I found a table on the 5th floor and got to work" (Mark, Research Reports).

"I sat down in my kitchen and took notes as I read and looked over the material" (Mark, Research Reports).

"Ecology is a part of chat that we have all experienced. For example, I went home this weekend so I am currently doing this assignment in my quiet room, if I was at school however, I would be doing it in my dorm room with loud people and music blasting. When we were in grade school the teacher usually made you be quiet when there was a writing assignment, however in high school the teacher let you talk if you needed to, and now in college you have to make the decision about the environment you want to be in while writing on your own. The ecology or environment could possibly affect the quality of my writing" (Claire, Blog 4).

Figure 20. Student awareness of work environments

During the focus group, the students emphasized that time management was an essential skill for a writing researcher. Under the umbrella of time management, the students discussed using effective planning to make sure that they finished all their work 
(see Sam's and Joe's comments in Figure 21). Within the blogs, students would sometimes reflect on their time management plans or strategies as they related to their writing processes (See Mark's comments in figure 21).

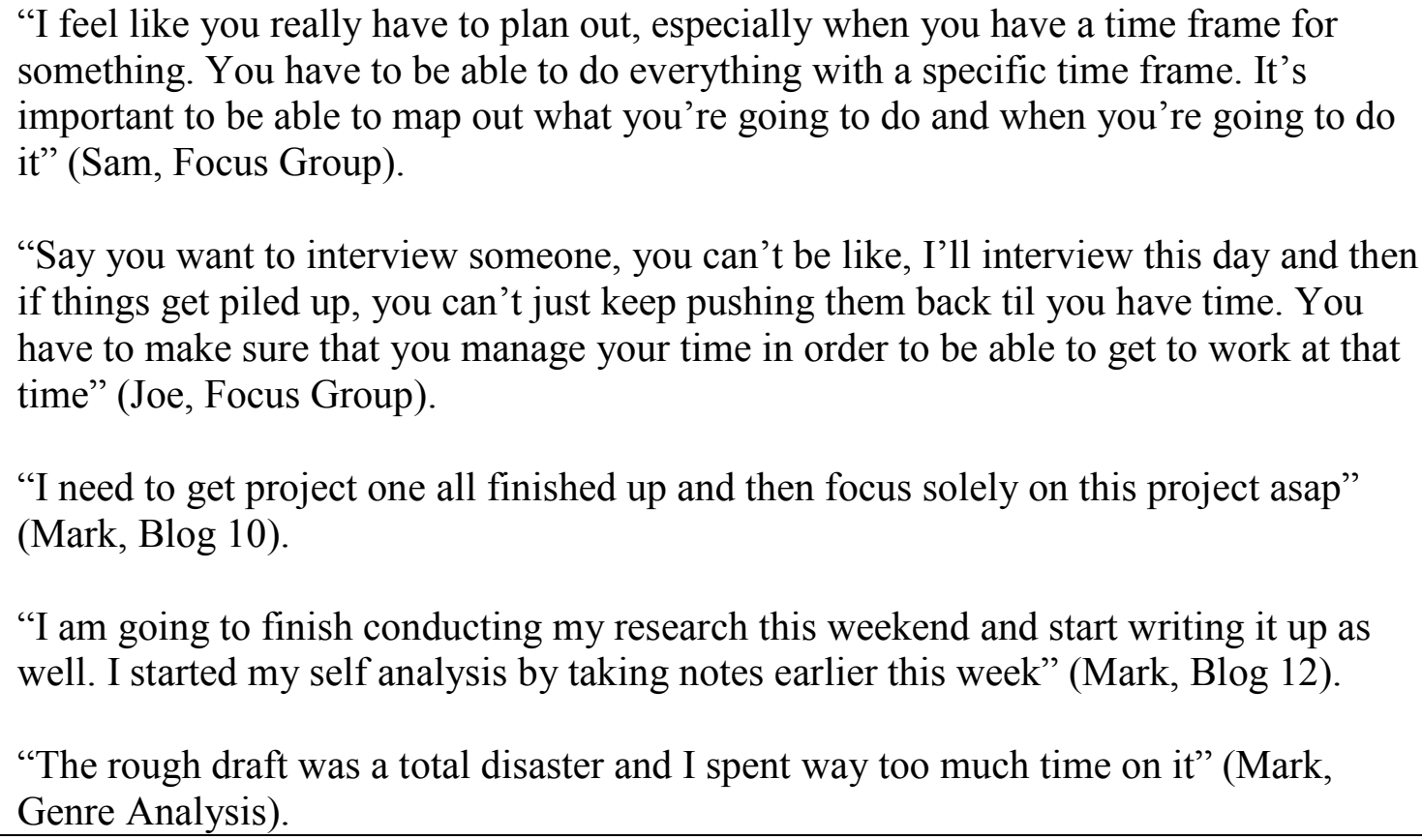
something. You have to be able to do everything with a specific time frame. It's important to be able to map out what you're going to do and when you're going to do it" (Sam, Focus Group).

"Say you want to interview someone, you can't be like, I'll interview this day and then if things get piled up, you can't just keep pushing them back til you have time. You have to make sure that you manage your time in order to be able to get to work at that time" (Joe, Focus Group).

"I need to get project one all finished up and then focus solely on this project asap" (Mark, Blog 10).

"I am going to finish conducting my research this weekend and start writing it up as well. I started my self analysis by taking notes earlier this week" (Mark, Blog 12).

"The rough draft was a total disaster and I spent way too much time on it" (Mark, Genre Analysis).

Figure 21. Discussions of time management

\section{Writing Researcher Identity Uptake}

During the latter half of our conversation in the focus group, I asked the students to reflect on whether and how they had taken up writing researcher identities both during and after the course. When I noticed that the students were focusing primarily on academic research writing, the conversation shifted to an exploration of the group's understanding of research. We observed that the students seemed to have taken up writing researcher identities in regards to formal or academic research, but they were less conscious of themselves as writing researchers in informal contexts. I asked them to explore how they had become writing researchers, and later, after the focus group, I 
compared their understanding of themselves as writing researchers as expressed in their semester documents vs. the focus group.

\section{Becoming Writing Researchers}

When I asked students when they became writing researchers, they unanimously agreed that they were not writing researchers at the beginning of the semester. Instead, they suggested that they started to take up the identity during our first major project:

Me: So when did you become one? When did that happen?

Sam: When we had to start doing the research for our first project.

Claire: Probably at that point because we had to start apply all that to our research for the first project.

Joe: I'd say I started doing more research around project 1 because I had the idea of what I wanted to do but at the same time you have to go in. For me, I knew I wanted to do an advice column or a medical treatment plan and I know about those things, but I don't know enough about them to sit down and do it. I had to go back and research how to set things up, like what's the normal format for things? I just started researching what I was going to be doing.

Me: So basically, you became a writing researcher when you had to do it?

Joe: Yeah

This conversation supports Freedman's (1993a) assertion that one does not acquire full knowledge of a particular genre or activity until one has the chance to perform that activity. The students felt that they took up writing researcher identities once they did the things that writing researchers do.

The students' emphasis on the first project is also interesting because it suggests that they took up the identities (or, at least, they remembered taking up the identities) before doing the co-research project together as a class. However, other points in our 
conversation suggested that the second project still did impact the students' writing

researcher identities. As Sam said:

I think it's kinda appropriate to consider ourselves as a writing researcher because we had to do formal research like sending out surveys and interviews, and we had to have people sign consent forms and like if we had to so something similar to this in high school, we wouldn't have had to have people sign an consent form or something like that, but I do feel like I could consider myself a writing researcher. (Sam, Focus Group)

The formality of the second project seemed to give students a greater sense that they were doing real writing research.

\section{Formal Identities}

Sam's comment was one of several that focused on writing researcher identities primarily as they pertained to formal or academic research. I tried to draw the students' attention to the definition of research that they were using to see if we could explore their research practices outside the classroom as well:

Me: So in the context of being a writing researcher, what do you think research is?

Mark: Knowing how to apply the information in the correct format. Like citing it and things like that. ... Preparing yourself for criticism. If you're writing a paper and you do the research, you're prepared for criticism because you made sure all the stuff you're writing about was correct. You use sources and things like that.

Mark again emphasized formal or academic research. Elsewhere in the conversation, he commented that he felt more confident as a writing researcher now because he felt more adept than his COM 110 classmates at using the Milner Library databases.

As I discussed earlier in this chapter, the students' definition of research at the time of the focus group seemed to be heavily influenced by both their concept of research prior to the class and their more recent experiences with research in COM 110. As I 
looked back over their work from the course, I noticed that their definitions of research and writing researcher identities in their blogs were also primarily formal, though at that time, they also contained traces of the informal. Claire was not sure she considered herself a writing researcher at the conclusion of the semester because she doubted her ability to integrate data into research write-ups (See Figure 22). This suggests a more formal conception of writing research. Mark, on the other hand, explicitly names informal research in Blog 13, but he still situates the research in a college context. In Blog 14, he anticipates transferring his ENG 101 skills into speech class (COM 110) specifically and into other non-specific situations.

"After this semester, I still don't know if I would consider myself a writing research
because I still have trouble applying and using the information that I have found in the
text that I am producting, but I feel like thanks to this class I have become a lot better
at it. I remember that a lot of comments on the draft for my article was "use specific
examples that you collected from your research". I'm still not $100 \%$ sure if I did it
accurately, but I sure tried" (Claire, Blog 15).
"I can see myself doing a lot more qualitative research in college both formal and
informal. The why and how is very important in any chosen major" (Mark, Blog 13).
"This experience was so thrilling from the overwhelming anxiety of putting the
research off to the relaxing and energizing creative process. I gained so much in terms
of knowledge and confidence in my abilities. The confidence will transfer over to next
semester when I am required to give speeches and when I am called upon to do
research of any sort" (Mark, Blog 14).

Figure 22. Statements about writing researcher identities in class blogs

Blog 15 asked students to reflect on their identities as writing researchers. Mark wrote, "A writing researcher is a writer willing to explore all the aspects of a genre and create a product that will work in the genre or at least take on the process of this. One of the most important parts of research is failure and learning from it” (Blog 15). This definition leans much more towards a holistic view of research as both a formal and 
informal process. He also puts more emphasis on the process, and suggests that a successful final product may or may not be necessary. The definition of a writing researcher that he emailed me after the focus group still emphasizes the process, but it is also infused with values that reflect the COM 110 course:

I thought of one more definition of being a research writer: Being able to take a concept or idea and apply efficient and effective methods of research such as using the data base at Milner, brainstorming, and making a CHAT map then being able to combine the data and produce an appropriate and well written product for the intended audience. (Mark, Email after Focus Group)

As I mentioned in the section on skills and knowledges, our ENG 101 course did not place much emphasis on using library databases or specific brainstorming strategies. We did discuss audiences, but probably not to the same extent or in the same ways as they are discussed in COM 110. The shifts in Mark's definition of a writing researcher over the matter of a few months demonstrate how identity uptake is constantly in flux. The students had formed a conception of research prior to the course, they re-formed it during the course in light of new ideas, and they re-formed it yet again after the course. These identity shifts reinforce both Prior, et al.'s (2007) idea of lamination and Kill's (2006) discussion of uptake memory (both discussed earlier in this chapter). The students' writing researcher identity formation was distributed over multiple contexts—-past, present, and future - and it is thus infused with learning and concepts from each of those settings.

\section{Going Dormant}

When I noticed that the students were primarily emphasizing the formal/academic sides of their writing researcher identities, I asked them consider why they were thinking of research strictly in academic contexts: 
Sam: I feel like there's kind of a stigma that research is a formal concept because we're exposed to research more in a school setting and stuff. So I think there's just that connotation that it's more formal. It's definitely informal too, but we just don't think about it as much.

Joe: The informal stuff happens subconsciously.

Sam: I feel like it's like dormant. Like we have those skills and the capabilities to do it so if we needed to do something like that again, we would know how to do it. Like we would know how to go about the different research methods and stuff like that so even if it's not active like every single day, we know it's there.

Claire: That's true. I agree with that.

Mark: I agree as well. I learned a lot. I can apply all of this stuff to write a paper.

Sam's comments in particular highlight some important ideas. Firstly, the word research is already laden with years' worth of meaning long before the students come into our classes. This is not to say that a writing research based ENG 101 course attempts to completely alter students' conceptions of research; how they understood research prior to the course was valid. As an instructor, my goal was to deepen and broaden students' understanding of research. I wanted them to develop more robust formal writing research skills, which the evidence about their use of uptake of writing research strategies (e.g., interviews, data analysis, observations, etc.) seems to suggest that they did. However, I also wanted them to exercise a greater degree of transfer between their informal / nonacademic research practices and their school practices. Our conversation seems to suggest that the students did not consciously take up this aspect of the writing researcher identity.

Sam's second comment and Mark's final comment may give us some clue as to why the students took up the formal side of research more readily. Sam says that if they 
"needed to," they could call upon their inner-writing researchers to activate their skills and knowledges. Mark's comment about writing papers suggests that academic contexts give students an exigency for activating their conscious writing researcher identities. Sam comments elsewhere, "I think for little things like every day tasks, it's more subconscious, like if you need to find out information about something. It just kinda happens naturally." This idea supports Mark's research on uptake (discussed in chapter 3). Reflecting on his research findings, Mark writes in Blog 14, "All in all I think uptake is recalled and articulated in more of a subconscious manner than it is absorbed in." In other words, students may be applying their writing research skills in new contexts, butparticularly in informal contexts - they are doing so subconsciously. The students have the ability to activate their uptake and self-knowledge at any time, but unless there is a perceived exigency for doing so, the uptake remains tacit.

\section{Concluding Thoughts}

As the skills and knowledges section demonstrates, the students did consciously take up certain aspects of writing researcher identities. They felt they were primarily able to perform these identities consciously in academic contexts because their concept of research is still very much defined by their past and current (COM 110) experiences. Based on these findings, I offer recommendations for future work in the conclusion. 


\section{A FUTURE FOR CO-RESEARCH? CONCLUSIONS}

\section{AND RECOMMENDATIONS}

In response to the question how did literate activity happen in our online ENG 101 course, my co-researchers and I found the following. Adela's study showed us that students' disposition towards LMSs might influence their interactions with them just as much as does the functionality of the interface. Katie's and Claire and Sam's studies suggested that introverts felt especially comfortable expressing themselves in our OWC. Their work also suggests that antecedent genre knowledge on social networks and other digital genres may have influenced their ability to self-represent online. Wes's work demonstrates that high levels of quality peer interaction are possible and constructive in OWCs. Finally, Joe's and Mark's studies suggest that autoethnography and metaphors may help students take up the concept of uptake and use it productively.

Based on these findings, we might recommend the following. Firstly, these results might be used to corroborate existing research on similar topics. In some cases, such as Wes's study on peer interaction, the student co-researchers' work might provide either support or counter-narratives for existing research. Rendahl \& Breuch (2013), for example, suggest that students did not find peer interactions valuable in the OWCs that they studied. Wes mentioned regularly in his blogs (as well as in his article) that he took up many of the concepts in the class through his interactions with his peers. This demonstrates that, perhaps with a different class structure than the one used in Rendahl \& 
Breuch's (2013) study, peer interaction can foster peer-to-peer teaching and learning. Adela's, Katie's, Sam and Claire's studies all support the usefulness of Van Ittersum \& Lawson Ching's (2013) recommendation that learners (and I consider both teachers and students to be learners) be encouraged to critically examine their own antecedent digital genres. Doing so may help learners transfer critical literacies to new online spaces, whether classes or spaces outside of academia. Katie's study in particular points out how online participants' subtle choices about fonts and typefaces convey to both the instructor and to other students a particular representation of themselves. For the sake of students' interactions within the OWC but also in future electronic spaces, teachers might consider encouraging students to develop a critical awareness of how they both represent themselves online and also form opinions about others online.

Our results also have implications for teaching uptake awareness. While many students struggled to take up uptake, both Joe and Mark suggested that practicing autoethnography may help facilitate the process. Joe's use of metaphors also makes a case for presenting uptake (and potentially other concepts) through narratives. As Jarema's (2014) study of student transfer demonstrated, intentional high-road transfer requires students to take up a strong awareness of their own learning, a finding which makes effective teaching of uptake awareness all the more important. Indeed, I would assert that writing research models of FYC are significantly less effective at encouraging forward-reaching transfer if they do not encourage students to take up uptake awareness. Uptake is where the conscious transfer happens.

In response to the second research question-How did students take up and demonstrate writing researcher skills, knowledges, and identities? — this study offers 
several insights. Firstly, the students both consciously took up and demonstrated awareness of genres and their contexts. They did this through their genre analysis assignments and GWRJ article productions, but as Claire's discussion about "learning to email the professor" demonstrates, they also began to apply these principles to other genres and contexts. Downs \& Wardle (2007) advocate for teaching core concepts that are essential to our field; the students in this study demonstrated that they both took up these concepts and deemed them valuable in constructing writing researcher identities.

The students also took up self-knowledge and the ability to productively analyze their own thought processes. As their studies demonstrate, several of the students were able to use self-knowledge and self-analysis productively for both formal and informal research. Joe, for example, used self-knowledge to identify when he had mis-transferred antecedent genre knowledge (informal), but also employed strategic and detailed techniques as he analyzed his own work from the class to draw robust research-based conclusions (formal).

Various types of research skills, including primary research strategies, were also a major area of student uptake. The skills the students chose to emphasize mostly aligned with formal research practices, so unsurprisingly, their uptake of writing researcher identities was primarily formal as well.

In contrast, the students felt that their informal research skills remained dormant or tacit. Sam suggested that she felt she could activate her research skills if she needed to, but perhaps the students struggled to identify exigencies for activating their writing research skills and identities outside of school. The deeply ingrained concept of what 
counts as "research" led the students to draw boundaries around appropriate places to perform their researcher identities.

Finally, the students' discussion of their writing research skills, knowledges, and identities contained a mixture of values from their prior research experiences as well as their current (post-ENG 101) contexts. This amalgam of values suggests that students' writing researcher identities are informed by experiences prior to the course and are continuously reshaped after the course. In part, the emphasis on formal research skills emanated from students' past and present experiences, as their uptake memories (cf., Kills, 2006) of high school and COM 101 led them to develop narratives about their skill development that intermixed ideas from ENG 101 with other experiences. Thus, because their past and present contexts placed great value on knowledge of library databases and audience analysis, for example, the students took up these concepts with greater fervor.

Based on these results, I have several recommendations for both researchers and instructors. Firstly, I recommend teaching with deep, formal, primary research projects. While obtaining IRB protocols and ensuring that students learn and observe research procedures can be time consuming, these formal aspects of the research process can go a long way in socializing students into a writing researcher identity, at least in regards to formal research. As Freedman (1993a) suggests, and as the students themselves mentioned, students become real researchers by doing real research. The formal activities such as obtaining signed informed consent documents helped students "feel" like researchers because they were doing the things that researchers do.

Beyond that, we also need to explore ways to help students form more meaningful connections and transfer between formal and informal research practices. To that end, 
Mark's and Joe's recommendations about uptake may provide some approaches worth exploring. Teaching critical autoethnography early in a course may help students take up uptake earlier, so students can then dedicate more time to actively and consciously examining their informal research practices. Teachers often do well modeling formal research practices, but they might consider drawing more explicit attention to modeling informal research practices. In particular, instructors should draw students' attention to the fact that these informal practices are research and that "writing papers" is not the only exigency for doing research. In fact, in the great scheme of life, we might say that "writing papers" is one of the least important exigencies for doing research. All students will have to do research in their personal and professional lives beyond college. Helping them to conceptualize a greater breadth of activities that "count" as research may help them to activate their writing researcher identities in a greater variety of contexts.

Beyond answering the primary research questions, this study may also have implications for co-research as a pedagogical and methodological tool. From a pedagogical perspective, engaging students in a co-research project may not be vastly different than assigning a highly formal research project of any kind. The students in this study reported taking on a greater sense of writing researcher identity because of the formality of the project, which does not necessarily require one to use a co-research model. However, I believe that one of the key affordances of a co-research model in pedagogy is that it encourages instructors to position themselves as mentors and learners. As mentors, we might show students our own work (e.g., the strategies we used to figure out how to analyze our data when we did project $X$, how we dealt with time management issues when we needed to schedule interviews, etc.), believing that as co-researchers, 
they have the capacity to enact those techniques themselves. Furthermore, when we teachers position ourselves as learners, we validate the knowledge that students bring and perhaps even model the value of peer learning to those who may be resistant to learning from other students in the course.

From a methodological standpoint, I would suggest that the inherent power dynamics in the teacher-student relationship make using co-research problematic in the classroom. Teachers can distribute agency as much as they want, but they are still the ones doing the distributing. The ability to assign power is a power in of itself, meaning that in most settings, teachers and students will never hold equal amounts of agency. In this study, I defined a loose overall question to guide our investigation: How did literate activity happen in our ENG 101 course? Future studies may consider giving students greater say in defining the guiding research questions and selecting the sites of inquiry. Kalmbach (2007), for example, has his students brainstorm lists of 25 organizations they have been involved with. From their lists, students then each select a site for their inquiries. While Kalmbach uses this strategy to teach report writing in a technical communication course, a similar approach could easy translate to an FYC course interested in researching literate activity. Even this move may not fully empower the students, but it may be a step in the right direction because it allows students to research what they truly care about.

As long as we acknowledge that the relationship between teacher researcher and student co-researcher will never be fully egalitarian, I see no reason that co-research should not function as a valid methodology in classroom research. Teachers, students, and indeed, the greater research community stand to benefit from the discoveries we 
make with our students in and outside of our classrooms. Online courses particularly stand to benefit from co-research because the model offers much greater access to the embodied, physical sites where knowledge-making is happening. The co-researchers in this study provided valuable insights and offered alternative voices that might not have been fully present had other methodologies been used. 


\section{REFERENCES}

Agboka, G. Y. (2013). Participatory localization: A social justice approach to navigating unenfranchised/disenfranchised. Technical communication quarterly 22, $28-49$.

Andrews, G., \& Varenne, H. (2011). Education into the online world: On the appropriation of online text and the production of everyday knowledge. Global Media Journal 11(18), 1 - 15.

Bartholomae, D. (2007). Composition. In D. G. Nicholls, (Ed.), Introduction to scholarship in modern languages and literatures $\left(3^{\text {rd }}\right.$ ed.) $(103-125)$. New York City: Modern Language Association of America.

Bawarshi, A., \& Reiff, M. J. (2010). Genre: An introduction to history, theory, research, and pedagogy. West Lafayette, IN: Parlor Press.

Bawarshi, A. (2013, October). Uptake genres. Fall Speaker Series. Lecture conducted from Illinois State University, Normal, IL.

Bergmann, L. S. \& Zepernick, J. S. (2007). Disciplinarity and transference: Students' perceptions of learning to write. WPA: Writing program administration- Journal of the council of writing program administrators 31(1-2), $124-149$.

Blythe, S., Grabill, J. T., Riley, K. (2008). Action research and wicked environmental problems: Exploring appropriate roles for researchers in professional communication. Journal of Business and Technical Communication 22(3), 272 298.

Boylorn, R. M. (2008). Participants as co-researchers. In Lisa M. Given (ed.), The SAGE encyclopedia of Qualitative Research Methods. $(600-602)$. Thousand Oaks, CA: SAGE Publications.

Brown, N. (2006). "The Regionalization of Cyberspace: Making Visible the Spatial Discourse of Community Online.” Composition Forum 15 ,1 - 20.

Conference on College Composition and Communication Committee for Best Practices in Online Writing Instruction. (2013). A Position Statement of Principles and Example Effective Practices for Online Writing Instruction (OWI). Retrieved from http://www.ncte.org.libproxy.lib.ilstu.edu/cccc/resources/positions/owiprinciples 
DePew, K. E., \& Lettner-Rust, H. (2009). Mediating power: Distance learning interfaces, classroom epistemology, and the gaze. Computers and Composition 26, $174-$ 189.

Dolmage, J. (2012). Writing against normal: Navigating a corporeal turn. In K. L. Arola \& A. F. Wysocki (eds.), Composing(Media) = Composing(Embodiment): Bodies, Technologies, Writing, and the Teaching of Writing. Logan, UT: Utah State University Press. $110-126$.

Downs, D., \& Wardle, E. (2007). Teaching about writing, righting misconceptions: (Re)envisioning 'first-year composition as 'introduction to writing studies.' College composition and communication 58(4), 552-584.

Engeström, Y. (1999). Activity theory and individual social transformation. In Y. Engeström, R. Miettinen, \& R.-L. Punamaki (Eds.), Perspectives on activity theory $(19-38)$. Cambridge: Cambridge University Press.

Fals-Borda, O., \& Rahman, M. A. (1991). Action and Knowledge: Breaking the Monopoly with Participatory Action-Research. New York, NY: Apex Press.

Farkas, K.R.H. (2011). Preparing students for active and informed civic discourse. Teaching English in the Two-Year College, 38(1), 35-46.

Farkas, K.R.H.. (2013). Citizen (in) action: The limits of civic discourse in city council meetings. Critical Discourse Studies, 10(1), 81 - 98).

Freadman, A. (1987). Anyone for tennis? In I. Reid (Ed.), The place of genre in learning: Current debates $(91-124)$. Deakin University: Centre for Studies in Literacy Education.

Freedman, A. (1993a). Show and tell? The role of explicit teaching in the learning of new genres. Research in the teaching of English 27(3), $222-251$.

Freedman, A. (1993b). Situating genre: A rejoinder. Research in the teaching of English $27(3), 272-281$.

Gillam, K.. \& Wooden, S. R. (2013). Re-embodying online composition: Ecologies of writing in unreal time and space. Computers and Composition 30, $24-36$.

Glassman, M., \& Erdem, G.. (2014). Participatory action research and its meanings: Vivencia, praxis, conscientization. Adult education quarterly 64(3), $206-221$.

Grabill, J. T. (2007). Writing Community Change: Designing Technologies for Citizen Action. Cresskill, NJ: Hampton Press. 
Griffin, J., \& Minter, D. (2013). The rise of the online writing classroom: Reflecting on the material conditions of college composition teaching. College Composition and Communication 65(1), 140 - 163.

Jarema, L. (2014). Students perceptions and proof of learning: A study of the elusive barriers that impact knowledge transfer within first-year composition and communication courses (Master's Thesis). Illinois State University, Normal, IL.

Jarratt, S. C., Mack, K., Sartor, A., \& Watson, S. E. (2009). WPA: Writing program administration- Journal of the council of writing program administrators 33(1-2), $46-73$.

Kalmbach, J. (2007). Technical reports as rhetorical practice. In C. L. Selfe (Ed.), Resources in Technical Communication: Outcomes and Approaches $(21-36)$. Amityville, NY: Baywood Publishing Company.

Kill, M. (2006). Acknowledging in the rough edges of resistance: Negotiation of identities for first-year composition. College composition and communication $58(2), 213-35$.

Latour, B.. (1999). Pandora's Hope: Essays on the Reality of Science Studies. Boston: Harvard University Press.

Latour, B.. (2005). Reassembling the Social: An Introduction to Actor-Network-Theory. New York: Oxford University Press.

Longo, B. (2007). An approach for applying cultural study theory to technical writing research. In J. B. Scott, B. Longo, \& K. V. Wills (Eds.), Critical Power Tools: Technical Communication and Cultural Studies, 111 - 131

Meyer, J. H.F., \& Land, R. (2005). Threshold concepts and troublesome knowledge (2): Epistemological considerations and a conceptual framework for teaching and learning. Higher Education, 49: 373 - 388.

Miller, C. R. (1984). Genre as social action. Quarterly journal of speech 70(2), 151 167.

Nickoson, L. (2012). Revisiting teacher research. In L. Nickoson \& M. P. Sheridan (Eds.), Writing studies research in practice: Methods and methodologies. (101 112). Carbondale, IL: Southern Illinois University Press.

Pachler, N., \& Daly, C. (2011). Key issues in e-learning. New York: Continuum International Publishing Group.

Perkins, D. N., \& Salomon, G. (1988). Teaching for transfer. Educational leadership $46(1), 22-32$. 
Potts, L. (2014). Social media in disaster response: How experience architects can build for participation [Kindle version]. New York: Routledge.

Prior, P., \& Hengst, J. (2010). Introduction: Exploring semiotic remediation. In P. Prior \& J. Hengst (Eds.), Exploring semiotic remediation as discourse practice. (1 23). Houndsmill, UK: Palgrave Macmillan.

Prior, P., Hengst, J., Roozen, K., \& Shipka, J. (2006). “I'll be the sun”: From reported speech to semiotic remediation practices. Text \& talk 26(6), $733-766$.

Prior, P., Solberg, J., Berry, P., Bellwoar, H., Chewning, B., Lunsford, K. J, Rohan, L., Roozen, K., Sheridan-Rabideau, M. P., Shipka, J., Van Ittersum, D., Walker, J. R. (2007). Re-situating and re-mediating the canons: A cultural-historical remapping of rhetorical activity. Kairos 11(3). Retrieved from:

http://kairos.technorhetoric.net/11.3/binder.html?topoi/prior-et-al/index.html

Ray, R. E. (1992). Composition from the teacher researcher point of view. In G. E. Kirsh $\&$ P. A. Sullivan (Eds.), Methods and methodology in composition research (287 $-300)$. Urbana: NCTE.

Remley, D. (2014). Writing in web-based disciplinary courses: New media, new disciplinary composing expectations. Computers and Composition 32, $1-18$.

Rendahl, M., \& Breuch, L. K. (2013). Toward a complexity of online learning: Learners in online first-year writing. Computers and Composition 30, $297-314$.

Roozen, K.. (2010). Tracing trajectories of practice: Repurposing in one student's developing disciplinary writing processes." Written communication 27(3), 318 354.

Roundy Blyler, B. (2004). Critical interpretive research in technical communication: Issues of power and legitimacy. In T. Kynell-Hunt and G. J. Savage (Eds.), Power and legitimacy in technical communication: Strategies for professional status. (143 - 166). Amityville, NY: Baywood Publishing Company.

Ruey, S. (2010). A case study of constructivist instructional strategies for adult online learning. British Journal of Educational Technology 41(5), 706 - 720.

Russell, D. (1995). Activity theory and its implications for writing instruction. In J. Petragalia (Ed.), Reconceiving writing, rethinking writing instruction $(51-78)$. Hillsdale, NJ: Erlbaum.

Salvo, M. J. (2001). Ethics of engagement: User-centered design and rhetorical methodology. Technical Communication Quarterly 10(3), 273 - 290. 
Salvo, M. J., \& Ren, J. (2007). Participatory assessment: Negotiating engagement in a technical communication program. Technical Communication 54(4), 424 - 439.

Schryer, Catherine. (1993). Records as genre. Written communication 10, $200-234$.

Scott, J. B., Longo, B., Wills, K. V. (2007). Why cultural studies? Expanding technical communication's critical toolbox. In J. B. Scott, B. Longo, \& K. V. Wills (Eds.), Critical Power Tools: Technical Communication and Cultural Studies, 1 - 19.

Sherblom, J. C., Withers, L. A., Leonard, L. G. (2013). The influence of computermediated communication (CMC) competence on computer-supported collaborative learning (CSCL) in online classroom discussions. Human Communication 16(1), $31-39$.

Shipka, J. (2011). Toward a composition made whole. Pittsburgh: University of Pittsburgh Press.

Smart, G., \& Brown, N. (2008). Developing a 'Discursive gaze': Participatory action research with student interns encountering new genres in the activity of the workplace. In N. Artemeva \& A. Freedman (Eds.), Rhetorical genre studies and beyond. (241 - 266). Winnipeg, Manitoba: Inkshed Publications.

Smit, D. (2004). The End of Composition Studies. Carbondale, IL: Southern Illinois University Press.

Spinuzzi, C. (2005). The methodology of participatory design. Technical communication $52(2), 163-174$.

Swarts, J. (2013). How can tools shape and organize technical communication? In J. Johnson-Eilola and S. A. Selber (Eds.), Solving Problems in Technical Communication. (146 - 164). Chicago: University of Chicago Press.

Swenson, P., \& Taylor, N. A. (2012). Online teaching in the digital age. Thousand Oaks, CA: SAGE publications.

Van Ittersum, D., \& Lawson Ching, K. (2013). Composing text / shaping process: How digital environments mediate writing activity. Computers and Composition Online 2013(Fall). Retrieved from http://www2.bgsu.edu/departments/english/cconline/composing_text/webtext/

Vygotsky, L. S. (1978). Mind in society: The development of high psychological processes. Cambridge, MA: Harvard University Press.

Walker, J. (2014). Illinois State University Writing Program CCCC certificate of excellence application. 
Wardle, E. (2009). 'Mutt genes' and the goal of FYC: Can we help students write the genres of the university? College composition and communication 60(4), $765-$ 789.

Warnock, S. (2009). Teaching writing online: How and Why. Urbana, IL: NCTE. 


\section{APPENDIX A}

\section{UPTAKE BLOG ASSIGNMENT}

Bawarshi (2010) recommends using uptake genres as a space for students to actively explore the processes that go into their learning and writing. The weekly uptake blog assignment encouraged students to reflect on how they had learned through the week. The purpose of the assignment was to help students develop an awareness of their uptake so they could potentially exercise both forward- and backward-reaching transfer (cite).

Below are some of the guiding questions I used throughout the semester to help students identify and articulate their uptake processes:

- What prior knowledge or experience were you able to transfer in this week?

- How well would you say you understand the concepts covered this week? (Remember, you don't have to be like, "Yay! I know it all!" We're more interested in your ability to accurately assess where you are).

- What activities "triggered" your learning? Why do you think that happened?

- What concepts were you unable to take up? Why do you think you were unable to take those concepts up? (Remember, being able to identify what you don't know is a skill. Not understanding something is not a sign of failure. Being able to pin down what you don't know allows you to figure out how to know it).

- What strategies could you use to better understand what you didn't take up before?

- How might the ideas you've explored this week transfer into future situations (in class or outside of class). Be very specific!

- Talk about your uptake with research methods. What research methods have you used in the past (both formally and informally)? What research strategies do you expect you will need to use in the future? (in school, in your career, in life in general)

Project-specific Questions:

- Be sure to reflect on what went well / poorly in your research. What decisions did you have to make along the way? How did you know what decisions to make? What do you still need to find out with your research?

- Talk about the development of your topic idea. What idea did you start with? How did your idea morph and change? What caused it to morph and change? 
For the students' final entry (Blog 15), I asked them to explore their uptake in the context of the whole semester rather than just the most recent week. The text of that assignment is included below:

Your final uptake blog is like the compilation album of all your blogs. For this blog, you need to look back over your previous blog entries and provide specific examples to support your ideas. Here are the things I'd like you to consider:

- Tracing uptake: Trace the development of your understanding of 1-2 specific concepts throughout the course of the semester. What specific events/thought processes influenced your uptake of those concepts?

- Uptake fails: Was there anything you feel you didn't ever "get" or take-up? Why do you think this was the case?

- Backwards-reading transfer: What skills and knowledge did you transfer? Reflect on skills and knowledge you transferred into the class from your previous experience. You can also describe skills and knowledge you acquired early in the semester and used later in the semester. Also feel free to mention any instances of transfer from other contexts (other classes, work, personal life, etc.) into this class or from this class into other contexts.

- Your best practices: We all have things that help us learn best. Did you identify any practices this semester that help you learn or practice uptake more effectively? What are some strategies you used to overcome confusion? Conversely, did you identify any strategies/practices that don't work for you?

- Forward-reaching transfer: What are some specific skills and knowledge you acquired or practiced this semester that you can transfer into specific situations in the future? (Note: Specificity is the key to this section.)

- Writing researcher identity: What does it mean to be a writing researcher? In what ways do you feel you are or aren't a writing researcher?

\section{Antecedent genre warning!}

In the past, you may have been asked to write various "reflections" or other genres where you expressed what you learned. Although those may be appropriate antecedent genre for this blog, be cautious. I'm not looking for "Yay! I learned so much, and I'm going to use this stuff forever and always!" You could actually write a really successful blog on how you failed to take up some of the key concepts in the class. What I'm looking for here is an accurate, honest assessment of your uptake. Specifics are key. 


\section{APPENDIX B \\ GLOSSARY OF KEY ENG 101 CONCEPTS}

Activity System - An activity system is all the people, texts, tools, and rules that work together to achieve a particular objective. For example, if my objective is to make a cool YouTube video, I might need a book called YouTube for Dummies, a camera, a friend to co-star with me or help me film, video-editing software, internet access, a computer, etc. All of these objects/people/ideas work together to make my objective (the YouTube video) possible. If you remove any of them, the activity doesn't happen. The diagram below illustrates this:

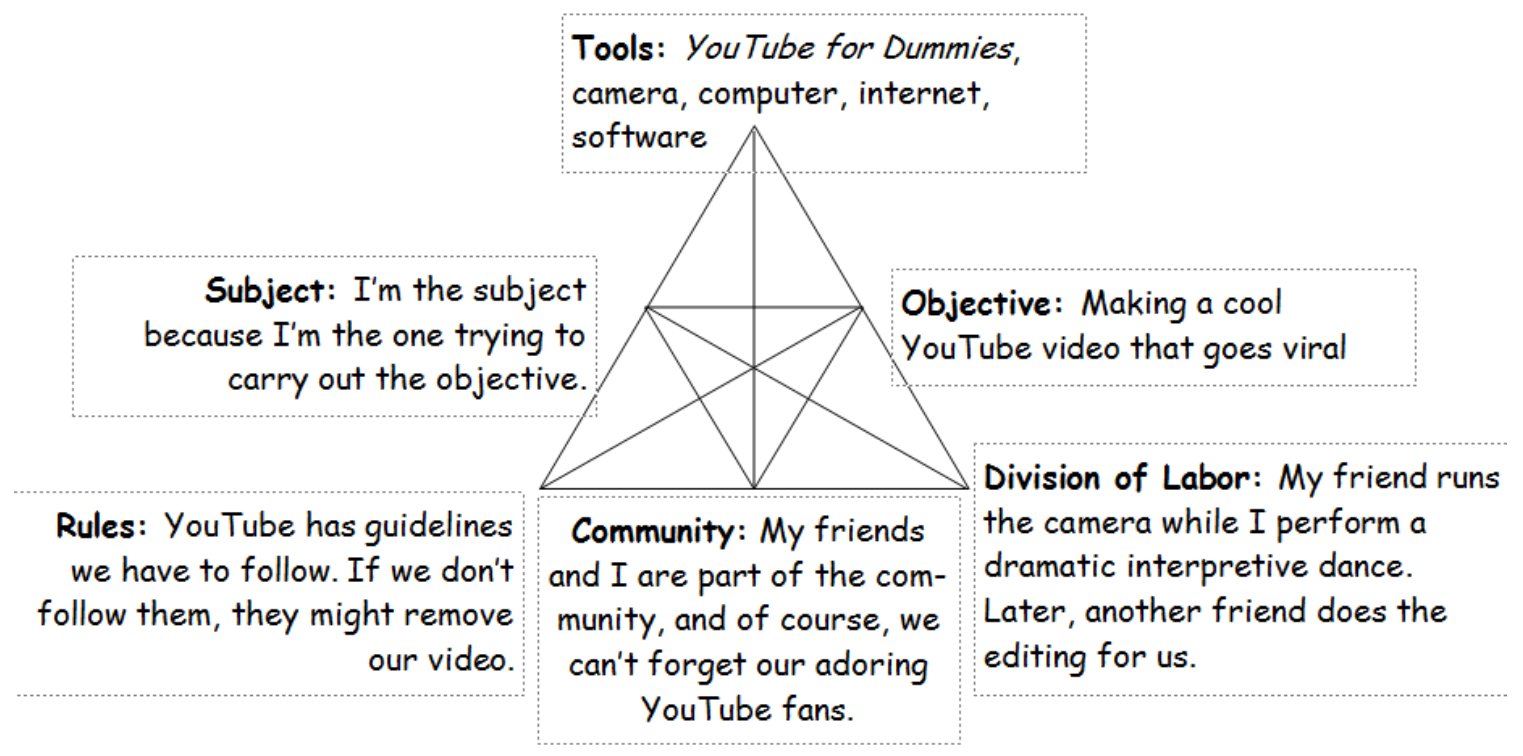

Antecedent Genre - When we enter new research/writing situations, we often think back to situations we've been in before that seem similar. The texts we produced in those past situations are our antecedent genres. We think about how we dealt with the earlier situation and how we could possibly deal with the new situation in similar ways. For example, if my biology professor asks me to write a lab report, I might think back to lab write-ups I did in high school and try to apply the techniques I used there to this new situation. . .which may or may not work.

CHAT definition 1 - CHAT stands for Cultural Historical Activity Theory. Activity Theory is an exploration of how people, objects, and ideas work together to carry out objectives (see Activity System for an example). But the "Cultural" and "Historical" part talks about how the objects, ideas, and genres we use reflect certain cultural values at a 
certain point in history. The fact that I made grilled cheese for dinner, for example, reflects my cultural values in this historical moment. . .I don't have much time, so I made something quick. . .I'm not vegan so eating cheese is okay with me... there's not a global cheese shortage on, so I could afford to buy it. . .I eat it without a fork because that's a cultural norm for grilled cheeses...etc.

CHAT definition 2 - Some folks find it easier to understand CHAT if they break it down into seven different sub-concepts: production, distribution, reception, representation, ecology, activity, and socialization. Let's revisit the example of making an YouTube video and look at it through these sub-concepts:

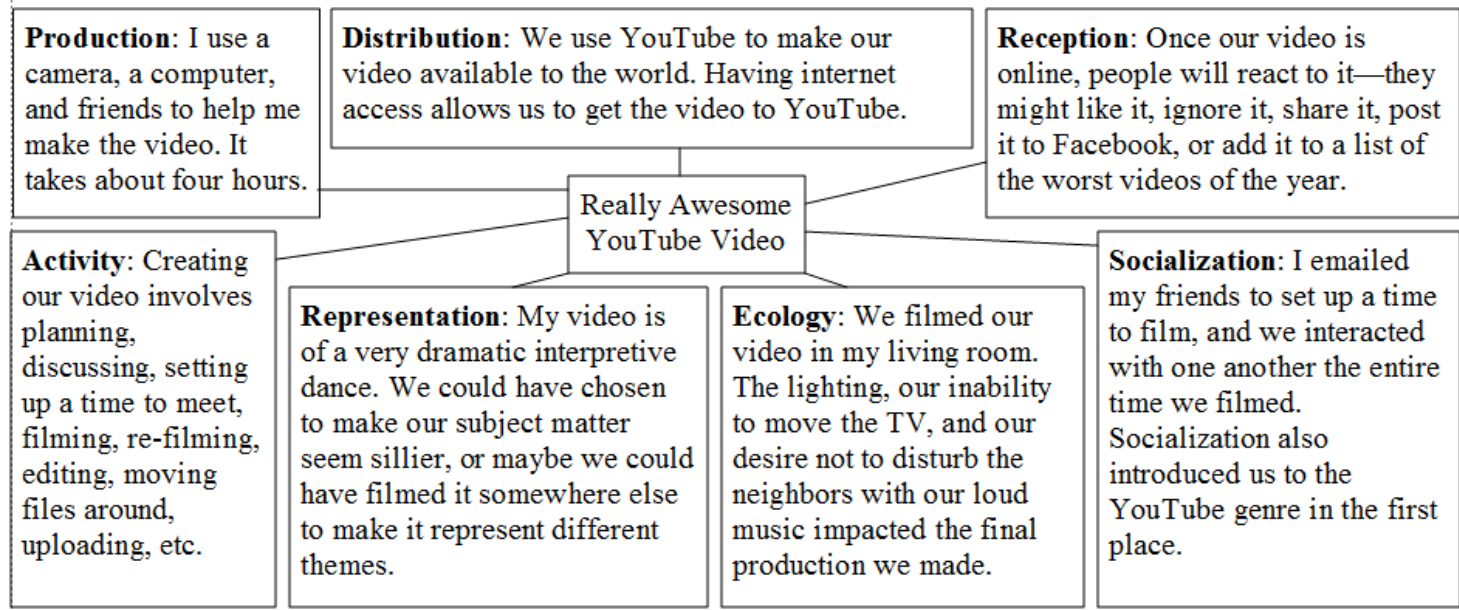

Genre - There are many ways of defining genre. I have three favorites:

1) A typified response to a recurring situation. . for example, when I apply for a job (the recurring situation since I haven't found a single job that seemed to stick yet), I write a resume (the typified - or typical — response to the situation). A less typified response to the I-need-to-apply-for-a-job situation would be sending the employer a very desperate "please please hire me!" letter via carrier pigeon.

2) A genre is a text that makes a particular action possible (or impossible). For example, if I want to send my husband to the grocery store to get our food for the week (and make sure that he doesn't just buy a week's worth of macaroni and cheese), I might make a grocery list telling him what to buy. On the flip-side, my landlord's no-pet policy makes it impossible (or at least a very bad idea) for me to own a puppy.

3) A genre is a "stable-for-now" category. As communities change and need to carry out different actions (or the same actions in different ways), the genres they use to make those actions possible often evolve. If you looked at a take-out menu from fifteen years ago, you might see the restaurant's address and a phone number. These days, that same take-out menu might also include a QR code, a website URL, and an invitation to "like" the restaurant on Facebook or follow it on Twitter. 
Uptake - Uptake is the process we go through to "take up" a new idea and think about it until it makes sense (if we get that far with it-sometimes we don't!). Our uptakes are highly individual because we all have different past experiences that impact the way we see the world. Say your instructor comes in and says, "There will be an ice cream social for our class on Friday afternoon." One student thinks, "I bet there will be waffle cones!" Another thinks, "Awesome! Class must be cancelled." Still another laments, "Ugh, forced socialization!" Notice that the instructor didn't say any of those things, but because of each students' past experiences or beliefs about ice cream socials, they take up the news to mean very different things. 


\section{APPENDIX C \\ GENRE ANALYSIS ASSIGNMENT}

Part I: Analysis of your genre

\section{Name of your genre:}

\section{Genre Samples}

Select three genres to consider in this analysis. Your samples should include the elements that are "prototypical" to your genre, but you may opt to choose one sample that still fits the genre but is less prototypical. Don't remember what "Prototypical" means? Re-watch The Word Bird video. Note: As you write your analysis, you should refer to your samples specifically in your writing as evidence to support your ideas.

Three Genre Samples - Using MLA, APA, or another academic citation style, cite the three sample genres you used. (Note: Depending on where you found your samples, you might have to be a bit creative about how you structure your citation). If you use more than three genre samples, please list all of them.

\section{Sample \#1}

\section{Sample \#2}

\section{Sample \#3}

\section{At the very bottom of this document (in the Appendix after Part II), please post pictures or URLs to your genre samples if possible.}

If you referred to any other sources to determine genre guidelines, please cite those here (Eg., Maybe you talked to a person who has experience with that genre; Maybe you Googled "How to write a lesson plan" and looked at a few sources. Please list sources you consulted even if you didn't end up using them):

Describe how you found the three samples you used for this analysis. 
Be detailed and specific. Answers like "I googled it" are inadequate. If you did Google it, why did you go that route? How did you process through the search results? How did you determine that they were appropriate samples? Which sources were the most useful?

Which were less useful?

\section{Conventions/Representation}

Describe in detail the parts/elements that make up your genre.

(Materials it is made out of, visual elements, language and grammar rules, etc.) What conventions are absolutely necessary (“It wouldn't be the same genre if it didn't have...) and which conventions are optional? How do you know?

\section{Antecedent Genres and Practices}

\section{Based on your understanding of your genre, what would you consider some} antecedent genres and practices that might help you write in this genre?

Remember, antecedent genres are genres you've used in the past that seem similar in some ways to the new genre. Antecedent practices are activities you've done before that might help you do a new activity (ex: If you've been a person who brainstormed before, maybe you'll identify that brainstorming might help you develop this new genre too)

\section{Audience(s)/Reception}

Who are the primary and secondary audiences for this genre?

Be specific. Most genres are not actually designed "for anybody!" Who are some specific people or types of people that this genre might target?

What are some possible ways this text could be received (both intended and unintended)

\section{Activities}

\section{What activities does your genre facilitate?}

Refer to specific conventions of the genre and explain how these conventions make it easier for the genre to facilitate specific activities. You can also note if your genre makes any activities difficult or impossible.

\section{Production, Socialization, Distribution, and Technologies}

What goes into producing this text? 
What steps or activities are involved? Be as detailed as possible and be sure to include steps (like information gathering) that precede the moment that the author(s) actually sit down to compose. What are the possible and ideal tools to use to produce this genre? What (if any) costs are involved? What materials are necessary? Who all is typically involved in the production of this text? (You may need to research this)

How does the genre get distributed? How does this distribution method depend on using specific materials and technologies in the production phase?

\section{Ecology}

In what environment is the genre typically produced? What conditions make it possible or necessary to produce the genre "this way"? What resources need to be available in the environment?

Describe the ecology of the environment where the text will be used. How do specific genre conventions make it possible for the genre to facilitate activities in that environment?

\section{Culture}

What cultural values are reflected in your genre? (Note: your genre may reflect the values of multiple cultures or sub-cultures).

\section{Research and Citations}

What research goes into developing content in this genre? (Remember, not all research is formal, library research).

Here are a few examples of genres I've used a lot:

- Grocery list - I look up grocery store ads to find out what's on sale. I decide what I'm cooking for the week (often this involves looking up recipes--I usually use Pinterest). I check my fridge and cabinets to see what food we already have and what normal "staple" items we're out of.

- Spanish lesson plan - This usually fits into the context of an overall unit. I determine what learning outcomes I want students to achieve (based on State Standards). I look for resources that will help students work towards that learning outcome using a variety of learning styles. Sometimes, I use materials from my curriculum. Sometimes I search for ideas on Pinterest. Sometimes, I check out resources available on some of my favorite websites like TeachersPayTeachers, 
StudySpanish.com, Barbara Kuczan's website, etc. I also consider how my students have done on past assessments and with past activities. What do they struggle with? What do they like?

\section{How does your genre cite or reflect research?}

Here are a few examples:

- A recipe blog will often use hyperlinks or just mention in the text where they got a particular recipe.

- A grocery list really just "reflects" the research that you've done. (A poorly researched grocery list would mean you come home from the store with the wrong things)

- In a lesson plan, I would include the "codes" of the learning outcomes my plan relates to. I would include page numbers for textbook / curriculum references. I would probably include the website URL of materials I copied from online.

\section{Part II: Analysis of your genre production}

You should NOT complete Part II for the first draft of your genre analysis. Ideally, you should complete this section after you have completed the second draft of your product.

Describe a VERY SPECIFIC place where you imagine your product would be used. For example, if you wrote a basketball season review, your product should be designed for a specific place where a season review might appear (ex: ESPN.com, the Pantagraph, etc.)

\section{Describe the content research you did to produce your product}

Note: content research is different than genre research. The first question under "Research and Citations" above gives some examples of types of content research. What specific things did you have to do to develop content for your product? Include any issues you encountered and how you worked through them. Also note any ways you feel your content development process was different than it would be for people normally producing this genre.

\section{Describe in detail the process you went through to put your product together.} What went well? What didn't go well? How did you decide how to proceed?

\section{How did your antecedent genres impact your process?}

Remember, we can transfer in knowledge from antecedent genres to help us. However, antecedent genres can also lead us to mis-transfer information that doesn't belong in the new genre. 
How did your understanding of your genre change as you created a product in that genre?

In what ways does your product match or mis-match conventions for your genre. It's not actually important to me that you are able to produce an exact match. What's more important is that you are able to articulate areas of matching / mis-matching and explain why any mis-matches happened. For example, you maybe don't have access to the materials usually used in the production of your genre.

\section{Appendix}

If possible, please post pictures or links to your three genre samples here. 


\section{APPENDIX D \\ RESEARCH REPORTS ASSIGNMENT}

You will create a total of three mini research reports based on each type of research you are using.

A few "little" requirements:

- There is no specific length requirement for your reports. Just write "enough" to explain your processes and ideas thoroughly.

- Please proof-read your reports so they are free of typos. Consider this a semiprofessional genre.

\section{Question and Methods}

In this section, you will describe your research question or the purpose of your investigation. In other words, what are you trying to find out? Explain why the type of investigation you're doing is an appropriate way to go about answering your question.

Explain in detail the methods you are going to use to carry out your investigation. For instance, who are you going to talk to? How are you going to contact participants? Where are you going to look for information? How much information do you need? How long are you going to spend collecting data? How many people are you going to talk to? How much information are you going to look up? What questions are you going to ask in an interview or survey? Etc.

Please also describe the procedure you are going to administer your informed consent documents if you are doing research that involves human participants (or the unpublished work/writing of human participants) other than yourself. YOU MUST INCLUDE A COPY OF YOUR INFORMED CONSENT DOCUMENT IN APPENDIX A.

If you create any interview / survey questions, please include that list in Appendix B. Note: particularly with interviews, it's okay if you deviate from your list a little bit during the interview as your subject sparks new ideas in your mind. The question list is just intended to give you a start. Note about surveys: If you are using SurveyMonkey to administer surveys (highly recommended!) you will be limited on the number of 
questions you can ask. Since your informed consent document will take up one question, you can probably only get in 9 more questions if you are using the free version.

\section{Summary of Data Collection}

Give a brief description of how your data collection process actually went down (This may be different than what you had planned.) Give a brief overview of the information you found and how you found it. Be sure to also describe anything that didn't go according to plan and what adaptations you had to make along the way. Were the obstacles you encountered so severe the it impacted the quality/validity of your data? Did your investigation fail to answer your research question (sometimes this happens! Failed research is still something we can learn from!)

\section{Analysis Methods}

Explain how you went about analyzing the data you collected. Why did you use this method? Analysis methods can vary considerably from project to project, so the best way to figure out how to analyze your data is to have a clear understanding of what you're trying to look for and to look examples of analysis in action. During week 12, I will also be giving you some video examples of analysis methods like coding. A few questions that might help:

- How can you look for trends in your data?

- What categories might you consider as you analyze your data? Where will these categories come from (e.g., Will you make them up ahead of time or will you just start working with the data and see what trends emerge?)

- How will you treat anomalies (instances that don't fit the norm)?

Note, in this section, you are NOT focusing on WHAT you found but HOW you went about finding it.

\section{Conclusions}

What answers did you find to your research question? What trends did you see? What anomalies? How do you expect your other research methods will help you understand your conclusion more deeply? Do you think there are other types of research you might need to do (but haven't done yet) to answer new questions that emerged from this research?

\section{ANTECEDENT GENRE WARNING!}

You may probably written "Conclusion" sections before (in those dreaded five-paragraph essays, for example). Please note that this conclusion section is asking you for different information than you may have included in your past writing experiences. This is not a "tidy summary of what I did." This conclusions sections is like the star of your report-this is all the stuff you found out! Often (if you're anything like me), you might have 
found that those five-paragraph essay conclusions were a bit "fluffy." But for this report, we're looking for meat in the conclusion (save the fluff for making marshmallows).

\section{References or Works Cited}

If you are doing a secondary research report, you need to have a References (for APA citations) or Works Cited (for MLA citations) section. Use either APA or MLA to format your citations. If you don't use any secondary research in your report, please get rid of this section.

\section{Appendix A}

Include any informed consent documents you had to create in this section. If your report didn't require an informed consent document, get rid of this section.

\section{Appendix B}

Include any interview / survey questions you created in this section. If your report did use any interview / survey questions, get rid of this section. 